\title{
Is Quality Accreditation Effective? Evidence from the Childcare Market
}

\author{
Mo Xiao*
}

\begin{abstract}
The ineffectiveness of a quality accreditation mechanism can be attributed to the inability of the accreditation status to provide consumers with information they do not already possess. I present a structural model of demand allowing consumers to infer quality from both accreditation status and firm reputation. I then estimate this model to assess the effectiveness and the impact of the national accreditation system for childcare centers on consumer welfare. My results suggest that disregarding the endogeneity of firms' accreditation choices significantly underestimates the effectiveness of the accreditation system. However, on average consumers do not gain much information beyond what they have inferred from a firm's reputation. The estimates of structural parameters are then used to quantify the value of this information to consumers.
\end{abstract}

JEL: $\quad$ L15 (Information and Product Quality); L8 (Industry Studies: Services)

This Version: July 2009

\footnotetext{
* Mo Xiao, Department of Economics, University of Arizona, Tucson, AZ 85721. Email: mxiao@eller.arizona.edu. I am deeply indebted to my dissertation committee members V. Joseph Hotz, John Riley, Dan Ackerberg and Kenneth Sokoloff for their consistent inputs. I thank Tasneem Chipty, Ann Witte, and Ellen Kisker for providing data. I also thank Andrew Ching, Hongbin Cai, Harold Demsetz, Paul Devereux, Phillip Leslie, Jean-Laurent Rosenthal, Duncan Thomas, Bill Zame, seminar participants at UCLA, Brown, Iowa State, Southern Methodist, USC, Rochester, and participants of the 2003 North American Econometric Society Summer Meetings for helpful comments. This research was funded by a grant from the National Institute for Child Health and Human Development (R01 HD035382). The author is solely responsible for the contents of the paper.
} 


\section{Introduction}

In a differentiated product market, consumers often do not readily observe product quality. This potentially gives rise to under-provision of high-quality products (Akerlof, 1970) and may reduce social welfare in a variety of ways (Stiglitz, 1989). However, various mechanisms could alleviate or even eliminate the informational problem consumers face (Grossman, 1981; Milgrom, 1981). One of these mechanisms, voluntary quality accreditation by a third-party authority, provides impartial but often imprecise information. A wide range of professions, such as water and wastewater utilities, teacher education programs, health maintenance organizations, and, apropos of this study, childcare centers, utilize this mechanism. Is voluntary accreditation an effective tool for providing information on quality to consumers? Do consumers receive sufficient benefit from this type of formal assessment for firms to derive incentives to seek accreditation in order to profit from it? This study examines these issues by empirically assessing the effectiveness and the welfare impact of the national accreditation system for childcare centers administered by the National Association for the Education of Young Children (NAEYC).

In the childcare market, the incentives to seek accreditation seem rather weak ---- 10 years after the accreditation mechanism was established, in 1996 only about $20 \%$ of childcare centers applied for NAEYC accreditation while merely $7.5 \%$ obtained the accreditation status. Other markets also suffer from low propensity of firms to seek accreditation. For example, prior to 1998 , less than half of operating health maintenance organizations had voluntarily applied for accreditation by the National Committee of Quality Assurance (Jin, 2005). If we believe that the accreditation status of a firm conveys a signal of high quality which consumers value, as the signaling literature has suggested $^{1}$ and experts in the childcare field have confirmed, then why do firms lack incentives to

\footnotetext{
${ }^{1}$ According the signaling literature, initiated by Spence (1973), a higher-quality firm would seek accreditation in order to signal its quality if its cost (benefit) to engage in the accreditation process is lower (higher) than that of a low-quality firm.
} 
seek accreditation? To answer this question, we need to be able to gauge the information relayed through the accreditation status. Consumers generally learn about product quality from multiple sources other than accreditation, such as experience, brand name, and word-of-mouth. If consumers have gained adequate information on product quality from other sources, they might gain little additional value from the information provided by knowledge of a firm's accreditation status. If so, a relevant policy issue is how to improve the informational content of quality accreditation, or to reconsider the necessity of accreditation if market forces have already dealt well with the information problem.

Unique features of the childcare market offer a good platform for the investigation of the above issues. Parents rely heavily on a provider's reputation to gain information on unobserved quality attributes. Meanwhile, they collect additional information through providers' accreditation status, as determined by the NAEYC. Based on these features, I formulate a model of individual consumer choice in which consumers infer product quality from two channels ---- one is the firm's accreditation status, and the other is its reputation, which has been established over the years. The way that accreditation status enters consumers' utility function depends on the quality level measured by the status and how much consumers rely on the status relative to the firm's reputation for information. Specifically, consumers' reliance on accreditation status relative to firm reputation depends on the relative magnitudes of the variances of these two signals. I then aggregate over individual consumer utility functions to derive product demand functions.

Using a random sample of childcare centers, I estimate these demand functions using full information maximum likelihood estimation with fixed effects, accounting for the endogeneity of both the accreditation status (by instruments) and prices (by fixed effects). These demand functions allow me to detect how product attributes, prices and accreditation status, as well as the reputation of a childcare center, enter consumers' utility functions. Using the number of years a center has been operating as a proxy for the precision of the center's reputation, I am able to identify patterns on how 
consumers' valuation of the accreditation status varies with the precision of the center's reputation. My main hypothesis is that the longer a firm has operated in a market, the more consumers know about its true quality. Consumers put $100 \%$ reliance on the accreditation status of a brand-new childcare center, as it has yet to establish any reputation. As the noise of the reputation signal decreases over time, consumers gradually shift reliance from the accreditation status to firm reputation. If my hypothesis is right, this relationship should be reflected by the fact that the accreditation status contributes less for older firms to attract demand given the same prices.

Estimation of the demand functions for childcare services leads to four main findings. First, consumers indeed gain less information from the accreditation status for a firm with a longer operating history. Second, incorporating the endogeneity of firms' accreditation choices restores the correct weight of the accreditation status against a firm's reputation. Third, on average consumers only put one third weight on a firm's accreditation status. Fourth and last, although the information provided by the accreditation status results in better consumer-product matches, my counterfactuals show that the existence of the national accreditation system improves consumer welfare by a mere $2 \%$. If the operating expenses of NAEYC and the expenses incurred during the accreditation process exceed $2 \%$ of consumer welfare, the accreditation system may not be justifiable.

Stepping away from this particular investigation of the accreditation system in the childcare market, I observe two discrepancies between theory and the real world. First, the disclosure literature predicts complete voluntary disclosure with negligible disclosure costs (Grossman, 1981; Milgrom 1981) while in the real world disclosure is rarely complete; second, in contrast to the theoretical insight, many empirical studies show that increased information has small or negligible effects (Devine \& Marion, 1979; Chipty and Witte, 1995, 1998; Milyo \& Waldfogel, 1999). ${ }^{2}$ Researchers

\footnotetext{
${ }^{2}$ Devine and Marion (1979) conducted an experiment in which they published comparative supermarket price information in local newspapers and found a small decrease in the mean and variances of prices. Chipty and Witte (1998) analyze the insignificant effects of location, availability, and quality information provided by local childcare resource and referral agencies (CCR\&Rs) on prices, price dispersion and quality of local childcare
} 
attribute these discrepancies either to firms' strategic considerations, ${ }^{3}$ to econometric complications due to endogenous information provision, or to the competing roles of information provision. ${ }^{4}$ In contrast to existing approaches, I investigate the behavior of consumers for an alternative explanation for these discrepancies. My viewpoint offers a perhaps more fundamental explanation: consumers may already know enough from other channels of information. In such a scenario, I suggest relevant policies should focus on the lack of information conveyed by the accreditation status, instead of the lack of parents' appreciation of quality as defined by childcare professionals.

My work is closely related to a recent branch of empirical work on how and what consumers learn from a particular type of information provision (Crawford \& Shum, 2005; Ackerberg, 2001, 2003; Chernew, Gowrisankaran \& Scanlon, 2008; Jin \& Leslie, 2008). These works, as a whole, highlight consumers' different sources of information such as advertising, quality rating, experience and reputation, and, more importantly, the different ways in which they learn from information. My study adds to this line of research by comparing the relative importance of firm reputation and quality rating when multiple sources of information are available. ${ }^{5}$ I find that this realistic setup plays an important role in shaping consumers' learning processes and limiting the welfare impact of one particular type of information provision. In this way my work also furthers the line of research which places the (sometimes unintended) impact of increased information under scrutiny (Dranove, Kessler, McClellan, \& Satterthwaite, 2003; Jin \& Leslie, 2003). ${ }^{6}$

markets. Milyo and Waldfogel (1999) analyze the effect of exogenous change in advertising on liquor prices and find that prices decrease insignificantly due to advertising.

${ }^{3}$ These considerations include certain types of disclosure costs (Jovanovic, 1982), costs of information acquisition by sellers (Matthews and Postlewaite, 1985; Farrell, 1986, Shavell, 1994), alternative market structures (Jin, 2005), and consumers' multidimensional heterogeneity (Hotz and Xiao, 2005).

${ }^{4}$ For example, advertising may reduce consumers' search costs, or may signal high quality to consumers.

${ }^{5}$ As to firm reputation, my study is also relevant to the literature about the impact of consumer learning about firms' unobserved quality on demand (Hubbard, 2002), contractual outcomes (Banerjee \& Duflo, 2000), on-line auctions (Bajari \& Hortacsu 2003), etc.

${ }^{6}$ Dranove and co-authors (2003) find that the "report cards" on health care providers discourage them to treat more difficult patients and result in a reduction of patient and social welfare. Jin and Leslie (2003) find that despite hygiene quality improvement due to restaurants' hygiene cards, there is evidence for grade inflation and changes in inspector behavior, which might undermine the usefulness of the hygiene cards in the long run. 
The paper proceeds as follows. Section 2 introduces the childcare market, the accreditation system, the data sets I employ and the construction of variables. Section 3 develops a model of consumer demand. Section 4 outlines my empirical strategy. Section 5 presents results and counterfactual welfare analysis. Section 6 concludes.

\section{The Childcare Market and NAEYC Accreditation}

\subsection{A Sketch of the Childcare Market}

Fueled by the rise of female labor force participation, the childcare market has been growing substantially, especially over the last two decades. ${ }^{7}$ The number of center-based programs (as contrasted to home-based programs) rose $26 \%$ from 40,631 in 1987 to 51,297 in 1992 and then rose $21 \%$ to 62,054 in 1997 (O’Neill \& O'Connell, 2001). ${ }^{8}$ Primarily small businesses, childcare centers compete in localized markets, as parents overwhelmingly prefer to have their children cared for in their own residential neighborhood (Chipty, 1995; Hofferth et al., 1991). This study focuses on childcare centers because NAEYC accreditation only applies to center-based programs. ${ }^{9}$

Childcare centers provide multiple types of services as children of different ages require different types of care. For example, infants need basic care such as changing diapers and feeding while older children need developmental activities and more indoor and outdoor space (Chipty \&

\footnotetext{
${ }^{7}$ According to the Bureau of Labor Statistics, in $197028.7 \%$ of mothers with children under age six worked; by 1990 this number had grown to $58.2 \%$, and by $200064.4 \%$. Correspondingly, non-parental childcare became an increasingly common choice. In 1995, according to the National Center for Education Statistics, more than 12.9 million of the 21 million children under six were in non-parental childcare, and more than 6 million of these children were in center-based childcare. Nationwide, about half of all working families with children under age 13 paid for childcare in 1997 . The monthly average of such expense was $\$ 286$, about $9 \%$ of their earnings.

${ }^{8}$ Childcare establishments take two primary forms----center-based programs and home-based programs. Centerbased programs care for relatively large numbers of children in institutional settings while home-based programs care only for three to four children in home settings. Centers usually group children according to age while home-based programs mix children of all ages in an informal atmosphere. They are very different entities and subject to different sets of state licensing requirements.

${ }^{9}$ Some researchers may be concerned that the exclusion of home-based care seriously undermines our study. For example, in 1997, 488,734 out of 550,788 child care establishments nationwide were home-based businesses. I disagree because center-based programs should be counted as the main source of non-parental child care. Although the absolute number of home-based programs greatly exceeds that of center-based ones, the opposite is true in terms of the number of enrolled children. In 1995, 31\% of the 21,421,000 children under 6 were enrolled in center-based programs, while $18 \%$ were in home-based programs.
} 
Witte, 1994). The services are both horizontally and vertically differentiated. Centers differ in horizontal attributes such as geographic location and operating hours. At the same time, they differ in quality measures such as staff-child ratios, group sizes, square footage for children's activities, and staff training levels. ${ }^{10}$ Aside of these "hard" measures, there are also "soft" measures: are children in the program generally comfortable, relaxed, and happy, and are they involved in play and other activities; are all areas of child development stressed equally, with time and attention being devoted to cognitive, social, emotional, and physical development? There is no absolute consensus on exactly what distinguishes low quality from high quality, but researchers seem to agree that quality should be comprehensively assessed based on all aspects of child care. Although centers are subject to states' licensing requirements, ${ }^{11}$ recent evidence suggests that the quality of child care in the United States is low and quite varied (Helburn, 1995).

There exists considerable asymmetric information between parents and providers: parents have difficulty ascertaining quality even when they incur substantial search costs to learn about providers (Mocan, 2001). Parents may not be able to spend a significant amount of time at the center to observe various dimensions of the operation. Moreover, the multidimensional attributes of these services may be difficult to evaluate and/or monitor (Hotz and Kilburn, 1996). Parents receive most of their information about providers from informal sources: family, neighbors, friends, and coworkers. The 1990 National Childcare Survey Parents Study indicates that the majority of parents $(66 \%)$ said that they learned of their providers from friends, neighbors or relatives, while $13 \%$ used

\footnotetext{
${ }^{10}$ Research has investigated which quality factors are linked to positive outcomes for children. The characteristics listed, especially group size, staff-child ratio and staff training levels, are associated with positive outcomes for children and hence with higher quality (Peisner-Feiberg and Burchinal, 1995)

${ }^{11}$ Some may argue that the license status of a childcare center signals quality, as the accreditation status does. I agree that the license status can offer parents quality assurance. However, because licensing requirements are mostly about observable attributes (e.g., staff-child ratio, group size), I view the licensing status more as an observable quality measure instead of a quality signal.
} 
advertisements and $9 \%$ turned to resource and referral agencies (Hofferth et al., 1991). ${ }^{12}$

\subsection{Accreditation as a Indicator of High Quality}

NAEYC, the only national accreditation body for center-based childcare programs, has been managing a national voluntary accreditation system since 1986. A childcare program applying for accreditation needs to engage in an extensive self-study based on NAEYC's accreditation criteria. A team of trained volunteer validators verifies the accuracy of the program's self-study during a site visit. A 3-member national committee composed of recognized experts in childcare and early childhood education then reviews the validated self-study, including the program director's responses to the validation visit. If the program is judged to be in substantial compliance with the criteria, it will be granted accreditation for a three-year period. Once a childcare center is accredited, parents can easily recognize this status by noting the display of the Academy's insignia ---- a torch ---- on its stationery and promotional material. ${ }^{13}$

The accreditation criteria cover broad issues such as interaction between teachers and children, curriculum, relationships between teachers and families, staff qualifications and professional development, administration, staffing, physical environment, health and safety, and nutrition and food service. While the NAEYC accreditation process examines the total program, it places the greatest emphasis on the quality of interaction between staff and children and the developmental appropriateness of the curriculum. The consensus by childcare professionals is that the accreditation status is an indicator of high quality. The 1988 National Childcare Staffing Study (Whitebook et al., 1990) examines the quality of care in 227 childcare centers representing 643 classrooms in five U.S. metropolitan areas and finds that accredited centers provided higher-than-average-quality services to

\footnotetext{
${ }^{12}$ A study on the behavior of parents in south Chicago, Camden and Newark (Kisker et al., 1989) has a similar finding: half of those parents who found non-relative care learned about the program or individual caregiver from family members or friends.

${ }^{13}$ The current list of accredited programs is posted on-line and updated monthly. Also, NAEYC-accredited programs receive a large colorful poster depicting the characteristics of accredited programs along with a certificate of accreditation. NAEYC does not reveal the identities of centers with rejected applications.
} 
children. ${ }^{14}$ The 1993 Cost, Quality and Child Outcomes Study (Peisner-Feinberg \& Burchinal, 1995) examines 401 childcare centers representing 749 classrooms in four states and confirms the previous findings.

It is worth noting that though NAEYC accreditation has accumulated a critical mass for consumer awareness, a low percentage of centers are actually accredited. As of spring 2001, 7,700 programs serving more than a half million children had achieved NAEYC accreditation, and an additional 8,000 programs were in the application process. In 1996, 4,459 programs (approximately 7.5\% of around 60,000 U.S. child establishments with payroll) were accredited, and 8,635 programs were in the process of seeking accreditation (Bredekamp and Glowacki, 1996).

\subsection{Primary Data: 1990 Profile of Childcare Settings: Center-Based Programs}

I use the Profile of Childcare Settings (PCS) ${ }^{15}$ as the primary data set, which consists of a stratified nationally representative sample of childcare centers in existence in $1990 .{ }^{16}$ PCS collected extensive data on a number of topics including general characteristics, admission policies and vacancies, types of children served, subsidies, staff, curriculum and activities, meals, health and safety, and operating expenses (Lang \& Card, 1992). The final sample includes 583 regulated home-based family providers and 2,089 center-based programs. ${ }^{17}$ I only study fee-charging center-based programs as pricing information is necessary to estimate the model formulated in section 3. For non-price-charging centers, parents' willingness to pay is reflected in different ways such as queuing and parental

\footnotetext{
${ }^{14}$ They find that accredited centers have better-trained staff and lower staff turnover, and provide more developmentally appropriate activities and higher quality care giving than non-accredited centers do.

${ }^{15}$ The American Family Data Archive (AFDA), Sociometrics Corporation made PCS available for my study. The study was conducted by Ellen E. Kisker and Valarie Piper, Mathematica Policy Research, Inc. The study was funded by the U.S. Department of Education, Office of Planning, Budget, and Evaluation.

${ }^{16}$ For comparison see Blau and Hagy (1998), in which they estimate a model of consumer demand for qualityrelated attributes of child care using the counterpart consumer-level data in the same survey.

${ }^{17}$ The sample was selected in two stages. In the first stage, a sample of counties that are representative of counties in the United States was selected. Counties were stratified according to region, metropolitan status, and poverty level, and counties were selected with probability proportional to the size of the population under age 5 . In the second stage, child care providers are stratified according to whether they are home-based, center-based, Head Starts, and Pre-Ks. Then a random sample of providers is selected from each stratum.
} 
involvement, which can be considered implicit prices. If the effects of accreditation status on nonprice-charging firms are systematically different from the effects on price-charging ones, my results may be biased. ${ }^{18}$ Out of 2089 centers, I drop 1013 from the analysis because of they do not charge fees for services, ${ }^{19} 129$ because they focus on handicapped childcare instead of regular childcare, and 9 due to inconsistent or incomplete data reporting. I focus on the remaining 938 firm-level observations.

\subsection{Auxiliary Data}

Market-level heterogeneity plays a central role in the childcare market. Childcare markets are very localized markets geographically. Few parents will travel more than fifteen miles to send their children to daycare (Chipty, 1995; Hofferth et al., 1991). Based on the 1990 population Census, a typical zip code covers a radius of 3 to 4 miles, roughly consistent with the area that a childcare center could cover. Other possible geographic boundaries such as cities, counties, or metropolitan statistical areas are too large relative to the service area of a daycare center to use in defining the relevant market. This makes zip code areas the finest approximation of local markets in the childcare market. To account for the market-specific heterogeneity, I use the following data sets to complement the primary data set.

- Zip code level demographics from the public 1990 Population Census. This data contains information on income level, education level, race composition, urbanization, and female labor participation for each zip code. I also use data on the number and percentage (with respect to population) of children in different age profiles to construct market share variables. In addition, I

\footnotetext{
${ }^{18}$ Furthermore, poorer markets tend to have more non-price-charging childcare centers than rich ones. By keeping only price-charging centers, my data might over-sample rich markets.

${ }^{19}$ The majority of these non-fee-charging centers are Head Starts and public school centers, which are over sampled and therefore comprise a large proportion of PCS observations. Head Start and Pre-Ks are mainly concerned with the development of low-income children rather than the provision of child care on a part-day, part-year basis. They are more responsive to the availability of public funding than to market forces and usually charge no or nominal fees.
} 
construct a variable to measure population mobility and use it as a control for the stock and flow of local information as well as a potential factor to influence the informativeness of firm reputation.

- Zip code level data on the childcare market from the public 1992 Business Census. ${ }^{20}$ I use the number of childcare establishments at the zip code level and their approximate number of employees to construct the outside market share in each market. The number of childcare establishments also serves as an instrument for firms' accreditation decision.

- Childcare resource and referral agencies (CCR\&Rs) special survey. ${ }^{21}$ CCR\&Rs are generally grassroots, non-profit local organizations whose primary function is to help parents find appropriate childcare for their children. They provide a centralized source of information on location, price, and observable characteristics. Similar to population mobility, I use the existence of a local CCR\&R (county-level) as a control for the stock and flow of local information as well as a potential factor to influence the informativeness of firm reputation.

I merge the primary data set with the first two auxiliary data sets by zip codes, and with the last one (CCR\&R survey) by county codes.

\subsection{Variable Construction and Summary Statistics}

I focus my attention on the following center attributes (see table 1 for variable definitions):

- $\quad$ NAEYC accreditation status: a dummy variable, equal to one if the center is accredited and equal to zero otherwise.

- Firm characteristics: enrollment, enrollment racial composition, years of operation, staff-child ratio, licensing status, organization status (for profit or non-profit), chain status, whether listed in

\footnotetext{
${ }^{20} 1992$ Business Census is based on the 1990 Standard Statistical Establishment List. Therefore, the 1992 Business Census matches my 1990 data.

${ }^{21}$ Chipty and Witte (1998) conducted a survey reporting the existence of CCR\&Rs in 1990 in the 100 county groups used in PCS. I thank them for making the data available to this study.
} 
a local CCR\&R, subsidization status, distance to public transportation, and hourly salary of a randomly-drawn teacher. ${ }^{22}$

- $\quad$ Product specific variables: prices, enrollment, staff-child ratios, and part-time/full-time status of each age group of a childcare center. Each center provides 1 to 4 types of services based on the age of the enrolled children ---- infants, toddlers, preschoolers, and school-age children. ${ }^{23}$ Each age group could offer part-time services (0-20 hours per week), or full time services (20-40 hours per week). As required by state regulation and necessitated by the nature of childcare, the number of staff for each age group usually increases as the age of the children decreases ---- the younger the child, the more adult attention she needs.

I define product-firm as a unit of observation, yielding 2,196 observations across 938 centers. Table 2 shows that the average center hires 9 employees and enrolls 66 children, of whom the majority $(78 \%)$ are White. The average center has operated for 11 years. Most of the centers are licensed (88\%) and listed in a childcare resource and referral agency (70\%), while only $38 \%$ are forprofit organizations and $6 \%$ are part of a chain. Around 30\% receive subsidies from federal, state, and/or local governments, and $6 \%$ of the enrolled children are subsidized. A small proportion of the centers $(15 \%)$ are NAEYC accredited. ${ }^{24}$ A randomly drawn teacher has an annual salary of $\$ 10 \mathrm{k}$ (in 1990 dollars). A center typically faces 4 competitors in a zip code.

Table 3 looks at variables of panel nature. The largest age group is the group of preschoolers (age 3 to 5). Staff-child ratios decrease with the age of children----infants require more laborintensive care. Full time childcare typically costs about $\$ 50$ a week (in 1990 dollars). Price decreases

\footnotetext{
${ }^{22}$ As teacher salary usually increases with teacher qualification and experience, I use hourly salary of a randomly drawn teacher as a proxy for teacher qualification and experience.

${ }^{23}$ If a center offers multiple packages for the care of children of a particular age, I take the average of staff-child ratios and prices across packages for this age.

${ }^{24}$ This percentage is significantly higher than the national statistic NAEYC reports because I dropped head starts and pre-Ks, which are qualified for accreditation and counted by NAEYC.
} 
as the age of the children increases, and part-time services are more expensive than full-time ones. ${ }^{25}$

As table 2 and table 3 indicate, the accredited centers are different, but not substantially so, from the non-accredited ones. The accredited centers are significantly more likely to be licensed, hire more employees, and have higher staff-child ratios, which is consistent with the NAEYC accreditation criteria. Accredited centers also seem to enroll more children and charge higher prices than non-accredited ones, but the differences are not significant. Interestingly, accredited centers operate for significantly more years than non-accredited ones. This could be because the accredited centers have better quality and hence last longer, or because centers with longer operating histories have better quality and will pass accreditation criteria more easily.

\section{$3 \quad$ Model}

To sum up the discussion in the last section, the childcare market is characterized by numerous local markets, multi-product firms, differentiated products, and asymmetric information between buyers and sellers. As is the case in many personal services industries (cleaners, dentists, home care, etc.), in the childcare market informal information channels, such as seller reputation, interact with formal ones such as the national accreditation system. To accommodate these features, I formulate a model in which consumers infer unobserved product quality from two different channels: one is a firm's accreditation status, and the other is its reputation, which consumers learn gradually through the word-of-mouth effect among their family members, neighbors, friends and coworkers. My focus is not on characterizing firms' equilibrium decisions about utilization of the accreditation mechanism. Instead, I restrict my attention to the demand side ---- how consumers learn and how they value the accreditation status. Although the specifics of my model are tailored to the nature of data I have available, the central feature ---- that consumers gain information from multiple sources ---- should be

${ }^{25}$ Table 3 does not show this pattern because it summarizes statistics across different samples. The set of centers offering infant care is not the set of centers offering toddler care. If highly priced centers specialize in toddler care, table 3 does not necessarily show that infant care costs more than toddler care. 
applicable for general use.

Let $i$ index individual consumer, $j$ individual firm, and $g$ the type of services offered by a firm. At each local market, firm $j$ produces multiple services indexed by $g$, and consumer $i$ decides which product to buy from which firm. In the context of the childcare market, a center offers different services and charges different prices for children of different ages. Parents purchase certain types of services according to their children's ages.

\subsection{Product Quality and Consumer Perception}

Each product $g$ of firm $j$ is differentiated along multiple dimensions, which can be captured by a vector of product and firm attributes $Q=\left[X_{g j}, X_{j}, q_{j}\right]$. I define $\left[X_{g j}, X_{j}\right]$ to be observable attributes (by both consumers and econometricians), where $X_{g j}$ is product-specific (for example, the staff-child ratio of an infant group), and $X_{j}$ is firm-specific (for example, the license status of a firm). ${ }^{26}$ I define $q_{j}$ to be an imperfectly observable quality attribute, which, for example, can be the developmental appropriateness of the curriculum, the loving atmosphere of a childcare center, or both. I further define $q_{j}$ to be a firm-specific ${ }^{27}$ quality attribute that cannot be captured by $\left[X_{g j}, X_{j}\right]$.

In the relevant literature of child care, $Q$ is the process quality, which has long-term impacts on child development. $X$ is the structural quality, which is the concrete input into the production of the process quality $Q$. If one estimates a quality production function (for example, Blau and Mocan,

\footnotetext{
${ }^{26}$ Some may argue that the license status of a childcare center signals quality, as the accreditation status does. I agree that the license status can offer parents quality assurance. However, because licensing requirements are mostly about observable attributes (e.g., staff/child ratio, group size), I view the licensing status more as an observable quality measure instead of a quality signal.

${ }^{27}$ I define $q_{j}$ to be firm-specific because: 1 ) the accreditation agency gauges the quality of a childcare center as a whole; 2) reputation is also more likely to be firm-specific as parents tend to exchange their experiences in a general way. Casual conversation among them can easily go: "I know a really good daycare center in Santa Monica..."; 3) I think the unobserved quality of a services firm is more integrated at the firm level instead of at the product level; 4) I put product-specific unobserved quality into the idiosyncratic error terms.
} 
2002), one will find that $X$ does not fully explain $Q$ due to center idiosyncrasies. In our definition, $q_{j}$ is the idiosyncratic component of process quality, which is not captured by centers' structural quality attributes $X_{g j}$ and $X_{j}$. By this definition, $X_{g j} \perp q_{j}$ and $X_{j} \perp q_{j}$. Lastly, a firm perfectly observes its own $q_{j}$ while consumers, as well as its competitors, do not directly observe $q_{j}$.

To provide information about $q_{j}$, an authoritative national accreditation agency administers a voluntary accreditation system for all firms. Consumers perfectly observe the accreditation status of each firm, and they believe the accreditation status indicates quality improvement by a certain level. Specifically, consumers believe $q_{j} \sim N\left(\gamma A_{j}, \sigma_{j A}^{2}\right)$, where $A_{j}=1$ if firm $j$ is accredited, and $A_{j}=0$ otherwise. That is, $\gamma$ measures the level of quality improvement indicated by the accreditation status. A higher $\gamma$ means that consumers associate the accreditation status with a higher $q_{j}$. Such a belief is consistent with the signaling literature (Spence, 1973; Nelson, 1974; Riley, 1979), which shows that a higher-quality firm will find it easier to pursue accreditation than its lower quality competitor, either because the higher-quality firm incurs lower cost during the accreditation process or receives higher benefit due to repeat purchases generated by consumers attracted to the accreditation status. Furthermore, the accreditation status provides imprecise information about $q_{j}$. The imprecision can be attributed to the possibility of classification error ---- the accreditation agency makes mistakes ---- and the discrete nature of the accreditation status ---- the binary status cannot fully reflect the continuous quality. The variance term $\sigma_{j A}^{2}$ is also influenced by some firm- or marketspecific factors, such as the prominence of the window display of the accreditation status and the influence of accreditation awareness activities organized by local resource and referral agencies. Basically, $\sigma_{j A}^{2}$ measures the informativeness of the accreditation status.

Besides the accreditation status, consumers observe the reputation of a firm $S_{j}^{R}$, which is an 
unbiased but noisy signal about $q_{j}$. Specifically, $S_{j}^{R} \sim N\left(q_{j}, \sigma_{j R}^{2}\right)$, where $\sigma_{j R}^{2}$, the variance of the reputation, measures the informativeness of firm reputation. The magnitude of $\sigma_{j R}^{2}$ depends on various factors, such as the population mobility in the area that the firm serves and the existence of a local resource and referral agency. In particular, a prominent factor is how long the firm has been operating in the local market. I hypothesize that the longer a firm has been operating, the smaller the variance $\sigma_{j R}^{2}$, meaning that firm reputation reflects $q_{j}$ more reliably. In the extreme case, if a firm has just opened for business and has not yet established a reputation, the variance $\sigma_{j R}^{2}$ will be infinity and consumers will learn nothing from this extremely noisy signal. Lastly, I assume that firms observe their own $S_{j}^{R}$, and the $S_{j}^{R}$ of other firms, so that their accreditation and pricing decisions might hinge on their own reputation and that of their competitors. Note that the econometrician observes the accreditation status but not the reputation of any firm.

Consumers update their beliefs about $q_{j}$ based on the accreditation status $A_{j}$ and the reputation signal $S_{j}^{R}$ using Bayes' rule. I denote the consumers' perceived $q_{j}$ given $A_{j}$ and $S_{j}^{R}$ as $E\left(q_{j} \mid A_{j}, S_{j}^{R}\right)$. We can derive $E\left(q_{j} \mid A_{j}, S_{j}^{R}\right)$ as a weighted average of $A_{j}$ and $S_{j}^{R}$ :

$$
E\left(q_{j} \mid A_{j}, S_{j}^{R}\right)=\frac{\sigma_{j R}^{2}}{\sigma_{j R}^{2}+\sigma_{j A}^{2}} \gamma A_{j}+\frac{\sigma_{A}^{2}}{\sigma_{j R}^{2}+\sigma_{j A}^{2}} S_{j}^{R}
$$

The above formula embodies the key feature of my model ---- that what consumers learn from a particular signal depends on the value of this signal, as well as on the relative magnitude of the variance of this signal compared to the variance of the other signal. ${ }^{28}$ For example, if a firm has a good reputation, consumers will think positively about the inherent quality of the firm. However, if

\footnotetext{
${ }^{28}$ A caveat to my model is that consumers disregard information about how firms' propensity for applying accreditation is determined. This simplifies my analysis, but undermines consumers' inferential ability. For example, if well-reputed centers were less motivated to get accredited, rational consumers would discount the accreditation status for centers with good reputation.
} 
this reputation signal has a large variance, consumers will rely more heavily on the firm's accreditation status for information. If, as hypothesized, the number of years in operation is positively correlated with the precision of a firm's reputation signal, consumers will rely more on reputation and less on the accreditation status for firms with longer operating histories.

\subsection{Consumer Choices and Firms' Demand Functions}

I take a characteristics-based approach to view products as a bundle of all product- and firm- specific attributes. Consumers' utility depends on all the attributes as well as product prices and personal characteristics:

$$
\begin{aligned}
& U_{i g j}=X_{g j}{ }^{\prime} \beta_{1}+X_{j}{ }^{\prime} \beta_{2}+D_{j}{ }^{\prime} \beta_{3}+E\left(q_{j} \mid A_{j}, S_{j}^{R}\right)-\alpha \log P_{g j}+\varepsilon_{i g j} \\
& =X_{g j}{ }^{\prime} \beta_{1}+X_{j}{ }^{\prime} \beta_{2}+D_{j}{ }^{\prime} \beta_{3}+\left(\frac{\sigma_{j R}^{2}}{\sigma_{j R}^{2}+\sigma_{j A}^{2}} \gamma A_{j}+\frac{\sigma_{j A}^{2}}{\sigma_{j R}^{2}+\sigma_{j A}^{2}} S_{j}^{R}\right)-\alpha \log P_{g j}+\varepsilon_{i g j}
\end{aligned}
$$

In this utility function, $\varepsilon_{i g j}$ is consumer $i$ 's idiosyncratic preference for product $g$ of firm $j$ and is distributed with a standard type I extreme value distribution. ${ }^{29} \beta_{1}$ and $\beta_{2}$ are vectors of parameters respectively measuring consumer valuation of product-specific attributes $X_{g j}$ and firm-specific attributes $X_{j}$, and $\beta_{3}$ is a vector of parameters measuring how demographics $D_{j}$ shift consumers' overall tastes regarding child care services. I use $\alpha$ as a measure of consumers' responsiveness to prices. ${ }^{30} \log P_{g j}$ is the natural $\log$ of the price of product $g$ of firm $j$. I normalize consumer $i$ 's utility from not buying any of the products (the outside product) to be zero: $U_{i g 0}=0 .{ }^{31}$

Parents choose which type of products to purchase based on the age of their child and which firm to purchase services from. At each local market, consumer $i$ will buy product $g$ of firm $j$ if

\footnotetext{
${ }^{29}$ For example, some consumers may value the bilingual environment more than others.

${ }^{30}$ Parents of older children may be less price sensitive than those of infants as a result of switching costs, but I have no data to identify the differential effect.

31 The outside option can be parental care or family-based provider care.
} 
and only if $U_{i g j} \geq U_{i g k}, \forall k$. Following Berry (1994), I aggregate over individual consumer utility functions to derive the market shares for each product $g$ of firm $j$. This is a simple Logit model and I can derive:

$$
\delta_{g j}=\ln m s_{g j}-\ln m s_{g 0}=X_{g j}{ }^{\prime} \beta_{1}+X_{j}{ }^{\prime} \beta_{2}+D_{j}^{\prime} \beta_{3}+\left(\frac{\sigma_{j R}^{2}}{\sigma_{j R}^{2}+\sigma_{j A}^{2}} \gamma A_{j}+\frac{\sigma_{j A}^{2}}{\sigma_{j R}^{2}+\sigma_{j A}^{2}} S_{j}^{R}\right)-\alpha \log P_{g j},
$$

where $m s_{g 0}$ is the market share of the outside product, $m s_{g j}$ is the market share of product $g$ of firm $j$, and $\delta_{g j}$ is the mean utility level. As established above, $\delta_{g j}$ can be uniquely determined by $\ln m s_{g j}-\ln m s_{g 0}$ and acts as a dependent variable.

In the above expression, I cannot identify $\sigma_{j R}^{2}$ from $\sigma_{j A}^{2}$ because scaling them proportionally will yield the same results, but I can identify their relative magnitudes. I define $h_{j}=\frac{\sigma_{j R}^{2}}{\sigma_{j R}^{2}+\sigma_{j A}^{2}}$, which leads to:

$$
\delta_{g j}=X_{g j}{ }^{\prime} \beta_{1}+X_{j}{ }^{\prime} \beta_{2}+D_{j}{ }^{\prime} \beta_{3}+h_{j} \gamma A_{j}+\left(1-h_{j}\right) S_{j}^{R}-\alpha \log P_{g j},
$$

where $h_{j}$ measures consumers' relative reliance on the accreditation status for information. The larger $h_{j}$ is, the more consumers rely on the accreditation status and the less on firm reputation. I further define $h_{j}=\Phi\left(h_{0}+h_{1} R_{j}\right)$, where $\Phi$ is the cumulative density function of a normal distribution, to ensure that $h_{j}$ lies between 0 and 1 as entailed by its construction. ${ }^{32} R_{j}$ is a set of variables which affect the relative informativeness of the two information channels. Candidates for $R_{j}$ includes the $\log$ of the years of operation of firm $j$, its chain status, population mobility of the local market, and the existence of CCR\&Rs at the county level.

\footnotetext{
${ }^{32}$ I have experimented with different functional forms for $h_{j}$ and obtained similar results.
} 


\section{$4 \quad$ Empirical Strategy}

\subsection{Estimation of Outside Market Shares}

The first task of the empirical estimation of my model is to construct the dependent variable ---- the mean utility level $\delta_{g j}=\ln m s_{g j}-\ln m s_{g 0}$. Estimating the market share of product $g$ of firm $j$, $m s_{g j}$, is relatively simple. I directly observe the enrollment for every age group $g$ of firm $j$ and the market size for age group $g$. For the childcare market, a natural proxy for the market size is the

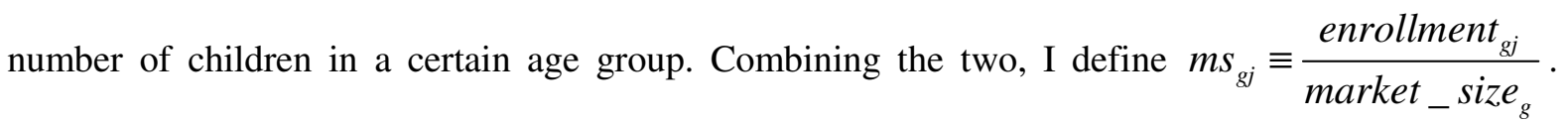
However, estimating the share of consumers choosing not to purchase services from any center, that is, the outside share $\left(m s_{g 0}\right)$, is challenging. The ideal data set has enrollment data for the universe of childcare centers in the local market so I can derive the share of consumers who choose to purchase from none of the centers. Recall that I only observe a random sample of firms, not the universe of them, which prohibits me from calculating $m s_{g 0}$ directly. In fact, all research trying to use sample data in a discrete choice model will run into the same problem ---- researchers only observe a subset of the choices facing consumers. To deal with this problem, I develop a method which combines the use of supplemental information on competing firms with non-parametric estimation. A crucial assumption I need to make is that the relationship between the numbers of employees and the numbers as well as age compositions of enrollment of the universe of childcare centers follows what I observe in my random sample. With this assumption, I employ the following procedure:

1. I use the 1992 Business Census to acquire data on the number of childcare centers at each zip code and the categorical number of employees of each center at that zip code.

2. I first estimate the relationship between the number of employees and the enrollment size of each 
age group at each center non-parametrically, using kernel density estimation. ${ }^{33}$ Assuming the same relationship holds for childcare centers out of sample, I then obtain a prediction of enrollment in each age group for every center in the zip code and aggregate them for all centers in that zip code. I define this aggregated number as enrollment ${ }_{g, \text { all }}$.

3. I calculate the outside share as $\widehat{m s_{g 0}}=1-\frac{\text { enrollment }_{g, \text { all }}}{\text { market_size }_{g}}$.

Table 3 shows that the share of the outside option is 0.91 for infants and toddlers, 0.72 for preschoolers, and 0.95 for school-age children. These numbers are realistic as infants and toddlers are more likely to be cared for at home or in informal settings while school-age children mostly go to after-school programs rather than day care centers during the time of the day when they need care. I find the above method, though the outside share is estimated rather than observed from data, a convenient and effective way to deal with the problem of observing only a subset of choices for studies using a random sample. My approach broadens the applicability of Berry (1994) and highlights the research potential for sample data. Fox (2007) proposes to compare the deterministic payoffs of pairs of choices when using data on a subset of choices, and shows that a semiparametric, multinomial pairwise maximum score estimator is consistent to estimate the structural parameters of a discrete choice model. His method may have more general applicability than mine as researchers do not always have outside data sources to provide them information on unobserved agents. ${ }^{34}$

\subsection{Equation to Estimate}

As the dependent variable, $\widehat{\delta_{g j}}$, as described in the above section, is an estimate, I introduce a

\footnotetext{
${ }^{33}$ I have tried several different kernel distributions and bandwidths for robustness checks. Results are similar.

${ }^{34}$ I cannot use Fox's approach because in my data I often only observe one firm in a local market, which renders pairwise comparison infeasible.
} 
measurement error term into equation (1), which leads to:

$$
\widehat{\delta_{g j}}=X_{g j}{ }^{\prime} \beta_{1}+X_{j}{ }^{\prime} \beta_{2}+D_{j}{ }^{\prime} \beta_{3}+h_{j} \gamma A_{j}+\left(1-h_{j}\right) S_{j}^{R}-\alpha \log P_{g j}+\omega_{g j},
$$

where $\omega_{g j}$ is the measurement error and $\omega_{g j} \sim N\left(0, \sigma_{\omega}^{2}\right)$. By estimating (2), which is a tractable linear form, I will be able to back out all the structural parameters in consumers' utility functions.

The purpose of estimating equation (2) is to find a set of parameter values $\left[\beta_{1}, \beta_{2}, \beta_{3}, \gamma, h_{0}, h_{1}, \alpha\right]$ so that the model best fits the data. To complicate the identification, both the price and the accreditation status variable are endogenous, as the econometrician does not observe the reputation signal $S_{j}^{R}$. First, firms will certainly base their pricing decisions $P_{g j}$ on reputation $S_{j}^{R}$. Second, as both the accreditation status $A_{j}$ and firm reputation $S_{j}^{R}$ are positively correlated with firms' unobserved quality $q_{j}, A_{j}$ and $S_{j}^{R}$ are also correlated (unconditional on $q_{j}$ ). Furthermore, firms may choose whether to seek accreditation based on their reputation $S_{j}^{R}$. A childcare center with a good reputation may be more motivated to seek accreditation because it is more likely to be able to pass the accreditation criteria due to its high quality. However, it may be less motivated because its reputation already conveys its high quality to consumer so accreditation is not necessary. For this study I am content to acknowledge this endogeneity problem but leave a fully-specified model on firms' accreditation decisions for future research.

With endogeneity in both the price and the accreditation status variable, ordinary least squares estimation leads to biased results. Therefore I develop a two-step estimation strategy, exploiting the panel nature of my data and instrumental variables to solve this technically challenging problem of double endogeneity. In the first step, I conduct fixed effects estimation to identify $\left[\beta_{1}, \alpha\right]$ using within-firm variation. In the second step, I conduct full information maximum likelihood estimation, using across-firm variation and instrumental variables for $A_{j}$ to identify the remaining 
parameters $\left[\beta_{2}, \beta_{3}, \gamma, h_{0}, h_{1}\right]$.

\subsection{Step 1: Fixed Effects Estimation}

To deal with the endogeneity problem of the price variable $P_{g j}$, I exploit the product-firm structure of the data. Viewing $S_{j}^{R}$ as fixed effects, I use the across-group-within-firm variation of $P_{g j}, \delta_{g j}$ and $X_{g j}$ to identify $\left[\beta_{1}, \alpha\right]$. Note that this approach is only valid by the assumption that there is only firm-specific unobserved heterogeneity to cause the endogeneity of prices. If a certain age group of a center is systematically more reputable than the other age groups and the center charges different prices for that, then this method will be flawed. I believe that in the childcare setting, parents choose where to send their children based on the reputation of an entire center because parents want continuity of services for their children as the children progress in age. Transferring children to different care centers is disruptive to the children's established schedule and relationships.

First, I take the mean of equation (2) across groups within firms:

$$
\overline{\delta_{. j}}=\overline{X_{. j}} \beta_{1}+X_{j}^{\prime} \beta_{2}+D_{j}^{\prime} \beta_{3}+h_{j} \gamma A_{j}+\left(1-h_{j}\right) S_{j}^{R}-\alpha \overline{\log P_{. j}}+\overline{\omega_{. j}}
$$

Substracting equation (3) from (2), I obtain:

$$
\widehat{\delta_{g j}}-\overline{\delta_{. j}}=\left(X_{g j}-\overline{X_{. j}}\right)^{\prime} \beta_{1}-\alpha\left(\log P_{g j}-\overline{\log P_{g j}}\right)+\omega_{g j}-\overline{\omega_{. j}}
$$

The firm-specific term $S_{j}^{R}$ disappears in equation (4). Therefore, OLS regression of $\widehat{\delta_{g j}}-\overline{\delta_{. j}}$ against $\left(X_{g j}-\overline{X_{. j}}\right)$ and $\left(\log P_{g j}-\overline{\log P_{g j}}\right)$ will yield consistent estimates of $\left[\beta_{1}, \alpha\right]$.

\subsection{Step 2: Full Information Maximum Likelihood Estimation}

After the first step, I then plug the consistent estimates of $\left[\beta_{1}, \alpha\right]$ back into equation (3) and construct: 


$$
\widehat{\lambda}_{j}=\overline{\delta_{. j}}-\overline{X_{. j}} \widehat{\beta}_{1}-\hat{\alpha} \overline{\log P_{. j}}=X_{j}{ }^{\prime} \beta_{2}+D_{j}{ }^{\prime} \beta_{3}+h_{j} \gamma A_{j}+\left(1-h_{j}\right) S_{j}^{R}+\overline{\omega_{. j}}
$$

in which $\widehat{\lambda}_{j}$ serves as the dependent variable in my second step estimation, and $\left(1-h_{j}\right) S_{j}^{R}+\overline{\omega_{. j}}$ is a composite error term with a heteroscedastic covariance matrix. ${ }^{35}$ In the above equation, firm reputation $S_{j}^{R}$, the econometrician-unobserved error term, causes the endogeneity of the accreditation status $A_{j}$.

My solution to this endogeneity problem is to use instruments for the accreditation status $A_{j}$. I embed a latent variable $S_{j}^{A}$ into firms' accreditation status, where $S_{j}^{A}$ is a firm's likelihood of receiving accreditation. Specifically, $S_{j}^{A}$ is a function of $\left[X_{j}, D_{j}, R_{j}, T_{j}\right]$, where $T_{j}$ are potential factors which affect a firm's incentive or effort to seek accreditation but do not affect its reputation. $T_{j}$, in short, serves as instruments for $A_{j}$, which I discuss in detail in the next section.

I observe $A_{j}=1$ if $S_{j}^{A}>0$, and $A_{j}=0$ otherwise. Assuming a linear function form, at the firm level we have: $A_{j}=1$ if $S_{j}^{A}=Z_{j}{ }^{\prime} \pi+\xi_{j} \geq 0$, where $Z_{j}=\left[X_{j}, D_{j}, R_{j}, T_{j}\right] ; A_{j}=0$ otherwise. This leads to a system of simultaneous equations with $h_{j}=\Phi\left(h_{0}+h_{1} R_{j}\right)$ plugged in:

$$
\begin{aligned}
& \widehat{\lambda}_{j}=X_{j}{ }^{\prime} \beta_{2}+D_{j}{ }^{\prime} \beta_{3}+\Phi\left(h_{0}+h_{1} R_{j}\right) \gamma A_{j}+v_{j} \\
& S_{j}^{A}=Z_{j}{ }^{\prime} \pi+\xi_{j}
\end{aligned}
$$

where $v_{j}=\left(1-\Phi\left(h_{0}+h_{1} R_{j}\right)\right) S_{j}^{R}+\overline{\omega_{. j}}$ and $S_{j}^{A}$ is latent. $\xi_{j}$ and $v_{j}$ are allowed to be correlated as firm reputation $S_{j}^{R}$ enters both equations.

As equation (6) is a system of simultaneous equations with heteroscedastic errors, for

${ }^{35}$ The variance of $\overline{\omega_{. j}}$ is $\frac{\sigma_{\omega}^{2}}{\kappa_{j}}$, where $\kappa_{j}$ is the number of groups for firm $j$. I have an unbalanced panel and firms have different numbers of groups $\kappa_{j}$. 
consistency and efficiency I conduct full information maximum likelihood estimation (FIML) to estimate the set of structural parameters $\theta=\left[\beta_{2}, \beta_{3}, \gamma, h_{0}, h_{1}, \pi\right]$.

$$
\widehat{\theta_{F M L E}}=\underset{\theta}{\arg \max } \sum_{1}^{J} \ln \left(\operatorname{prob}\left(\widehat{\lambda}_{j}, A_{j} \mid X_{j}, D_{j}, R_{j}, Z_{j}, \theta\right)\right) .^{36}
$$

To check the robustness of my estimates, I also conduct the Heckman-corrected model on equation (6) by assuming a linear form $h_{j}=h_{0}+h_{1} R_{j}$.

\subsection{Choice of Instruments for Accreditation}

Valid instrumental variables for the accreditation status $A_{j}$ are variables correlated with $A_{j}$ but not with firm reputation $S_{j}^{R}$. In addition, the instruments must be excluded from the equation to estimate. I use a combination of the following instruments and $\left[X_{j}, D_{j}, R_{j}\right]$, to constitute $Z_{j}$ in the system of equations (6). ${ }^{37}$

- Firm average state-set staff-child ratio licensing requirement: Sufficient staffing is an important accreditation criterion and therefore firm-average staff-child ratio should be positively correlated with a center's accreditation decision. However, it might also be correlated with a firm's reputation. I circumvent this problem by using the state-set staff-child ratio licensing requirement, ${ }^{38}$ averaged across age groups of a center, as an instrument. First, Hotz and Xiao (2005) show that the staff-child ratio requirements have substantial variation across states and that childcare centers are more likely to receive NAEYC accreditation in states with more stringent staffing requirements. Second, a licensed center certainly has to satisfy the requirements of the state in which it operates, while the state generally does not set the stringency of licensing

\footnotetext{
${ }^{36}$ See appendix 1 for the derivation of the log likelihood function of the FIML model.

${ }^{37}$ In one specification I also put interaction terms between $R_{j}$ and the instruments into $Z_{j}$, as there is interaction between $R_{j}$ and $A_{j}$ in the model.

${ }^{38}$ Dr. Hotz and Kilburn generously provide the regulation data set.
} 
requirements in response to the reputation of an individual center. Conditional on actual staffchild ratios, which consumers typically observe, a firm's reputation should be orthogonal to the firm-average of regulated staff-child ratio. Considering the above two reasons, this instrument should be ideal in theory. The only caveat is practical ---- it may not have sufficient variation across firms.

- The administrative accreditation cost per child in capacity: NAEYC charges a categorical accreditation fee based on the number of actual enrollees, not the number of children a center's capacity allows. ${ }^{39}$ I divide the total accreditation fee by the capacity of the center to get administrative accreditation costs per child in capacity. This cost should inversely affect firms' accreditation propensity and have no effect on the formation of firm reputation. Furthermore, the accreditation cost does not influence consumers' valuation of childcare services. Note the capacity of a center is usually determined before any accreditation decision and the actual enrollment is often different from the capacity, as shown by a correlation coefficient of only 0.66 between these two variables. This should alleviate the concern that this instrument has an endogenous factor built in the denominator. Therefore administrative accreditation cost per child in capacity is a natural instrument for accreditation.

- Market Structure: A firm's accreditation incentive is often driven by strategic considerations of competitive factors (Jin, 2005). For example, a new childcare center may want to seek accreditation in order to differentiate itself from its oligopolistic competitors with established reputation. This is a well-used instrument in the empirical discrete-choice demand model, in

39 In 1990, NAEYC fee schedule was:
\begin{tabular}{|l|l|l|l|}
\hline Enrollment & Application Fee & Validation Fee & Total \\
\hline 60 or fewer children & $\$ 125$ & $\$ 300$ & $\$ 425$ \\
\hline 61 to 120 children & $\$ 200$ & $\$ 450$ & $\$ 650$ \\
\hline 121 to 240 children & $\$ 250$ & $\$ 575$ & $\$ 825$ \\
\hline 241 to 360 children & $\$ 300$ & $\$ 700$ & $\$ 1000$ \\
\hline
\end{tabular}

For each additional 120 children above 360 , the application fee and the validation fee are each increased accordingly. I thank Pat Mucci in NAEYC for providing me the information. 
which researchers use the number of competing products in a group or local market to instrument for the short run pricing decisions (Berry, Levinsohn and Pakes, 1995). Similarly, the accreditation decisions are also formed in the relative short run, so we can reasonably argue that firms act strategically upon existing market structure. However, the formation of firm reputation is a decentralized process, which is often out of the direct control of firms. Reputation has more to do with the stock and flow of local information than with the number of competitors. Considering the above reasoning, I use market structure dummies as instruments for accreditation. Specifically, I define Oligopoly $=1$ if 1 to 3 establishments exist in the market, $=0$ otherwise Monopolistic Competition $=1$ if 4 to 6 establishments exist in the market, $=0$ otherwise. $^{40}$

In the above three groups of instruments, I am most confident about the validity of the firmaverage of regulated staff-child ratio and therefore I use it exclusively for the baseline estimation. However, this instrument suffers from the problem of insufficient firm-level variation and results in large standard errors of the estimates. To remedy this problem, I supplement the latter two groups of instruments. In the results section, I present three specifications. In the first specification, I use the firm-average of regulated staff-child ratio as the only instrument; in the second, I use all three groups of instruments named above (that is, four instruments in total); in the third, I use all four instruments named above plus their interactions with the number of years of operations (that is, eight instruments in total). I then conduct Hausman overidentification tests to assess the validity of the accreditation cost and the market structure instruments, comparing the second and third specification to the first respectively. The tests are not able reject the null hypothesis that differences in estimates produced by the first and the second/third specifications are not systematic. I consider these tests as strong support for the validity of the latter two groups of instruments.

Table 4 summarizes the variation in the instrumental variables I use. In a typical childcare

\footnotetext{
${ }^{40}$ I checked other break downs for the market structure variable and have obtained similar results.
} 
center, a staff member is required to care for at most 10 children. It takes slightly more than two dollars per child in a center's capacity to apply for accreditation. About one third of the centers operate in a market structure with at most three centers, while another third operate in a market structure with four to six centers.

\section{$5 \quad$ Results}

\subsection{Step 1: Fixed Effects Estimation Results}

I present the estimation results in tables 5, 6 and 7. In my estimation, I have experimented with different sets of variables in $R_{j}$, which determines the relative informativeness of the accreditation status and firm reputation. In particular, I tried the chain status of a center, population mobility and the existence of child care resources and referral agencies along with the log of the number of the years in operation of firm $j(\log ($ years $))$. With or without the first three variables in $R_{j}$, the estimation results are almost identical and the coefficients for the first three variables are never significant. As a result, I choose to focus on $\log$ (years), which turns out to have a consistently significant impact on the relative informativeness of the two information channels.

Table 5 reports results from OLS, between-groups, and fixed effects estimation. Both OLS and between-groups estimates produce a significantly positive coefficient of the price variable $\log \left(\right.$ price $\left._{g j}\right)$ due to the correlation between prices and the firm-specific unobserved error term ---firm reputation. Within-groups estimators give consistent estimates for all variables with withingroup variation. As column (3) of Table 5 shows, within-groups estimates produce a significantly negative price coefficient of -0.33 .

I find that most other estimated coefficients are consistent with what one would expect. As Table 5 shows, a longer operating history, licensed status, and better-paid employees contribute 
significantly and positively to consumers' valuation of childcare services, while part-time status, forprofit status, and subsidized status have the reverse effect. Furthermore, markets with a bettereducated population, higher percentage of Whites, higher female employment rate, and a CCR\&R have greater willingness to pay, but markets that have a higher percentage of African-American population and are more urban do not. Consumers also seem to place a higher value on centers located farther from public transportation, which are more likely to be located at quieter and safer residential areas. I suspect that the significant negative coefficient for staff-child ratio is due to the negative correlation between $\delta_{g j}$ and staff-child ratio, because by construction the enrollment in an age group enters the numerator of $\delta_{g j}$ but the denominator of staff-child ratio. For this reason, I do not intend to interpret a causal relationship out of the coefficient.

\subsection{Step 2 Results in Reduced Form}

Table 6 reports reduced-form estimation results from my step 2 estimation. Column 1 reports OLS results, and columns 2 to 4 report Heckman-corrected results using different sets of instruments. The reduced-form evidence confirms my conjecture. Both OLS and Heckman-corrected estimation report significantly positive coefficients for accreditation status, but significantly negative coefficients for the interaction term between accreditation status and $\log ($ years $)$. Columns 2 to 4 show that the results are consistent for different sets of instruments with more instruments leading to more significant results. Although I am not able to identify $\gamma$ and $h$ from these reduced-form results, it is safe to say that there is strong and consistent evidence that consumers do value the accreditation status but value it less for older firms.

The Heckman-corrected estimation produces larger coefficients for the accreditation status $A_{j}$ and the interaction term. I attribute this change to the potential negative correlation between $A_{j}$

and $S_{j}^{R}$---- firms with a better reputation have a lower propensity to seek accreditation. As for other 
firm-specific variables, their magnitude, signs and significance remain consistent across various specifications and estimation methods, and their signs and significance are close to what Table 5 OLS results report. ${ }^{41}$

\subsection{Step 2 Results in Structural Form: Maximum Likelihood Estimation}

Now I discuss the results of the structural estimation. Recall that $\gamma$ measures the level of quality improvement as measured by the accreditation status, while $h_{j}$ measures how much weight consumers assign to the accreditation status relative to the reputation signal to gain information about the unobserved quality of firm $j$. The larger $h_{j}$ is, the more consumers rely on the accreditation status for information. Furthermore, $h_{j}$ depends on the operating history of a firm: my hypothesis is that the longer a firm has been operating in a market, the more consumers rely on its reputation and the less on its accreditation status for information. In short, I expect $h_{1}$, the coefficient for the log of years in the $h_{j}$ function, to be negative.

Table 7 reports results from the maximum likelihood estimation. The first column reports results taking $A_{j}$ as exogenous, in which I set $\rho=0$ to restrict correlation between the two equations in (7). I find that $\gamma$ is significantly positive $(\gamma=2.922)$. I find both $h_{0}$ and $h_{1}$ significantly negative $\left(h_{0}=-0.882\right.$ and $\left.h_{1}=-0.240\right)$. The average value of $h_{j}$ is significantly estimated to be 0.092, which means that very little information is conveyed by a firm's accreditation status, and that consumers rely mostly on a firm's reputation for information. On average, consumers assign a weight of approximately $10 \%$ to the accreditation status and approximately $90 \%$ to firm reputation.

\footnotetext{
${ }^{41}$ There are several exceptions though. The coefficients for female labor participation lose significance, while that for the measure of population mobility gains significance.
} 
The last three columns report the results from the full information maximum likelihood estimation (FIML), in which I allow $\rho$ to be estimated. The estimates of $\beta$ are similar to column 1. However, $\gamma$ is estimated to be significantly larger than the result from the model with exogenous accreditation. In the last two columns, where I used fuller sets of instruments, both $h_{0}$ and $h_{1}$ are significantly negative and the average $h_{j}$ is estimated significantly to be 0.34 . In other words, consumers receive less information for firms with a longer history; for an average firm, consumers put around one third weight on the accreditation status and around two thirds weight on firm reputation. The changes in the magnitude of $\gamma$ and $h$ can be explained by a significantly negative $\rho$ :

an accredited center tends to have a lower draw of reputation signal $S_{j}^{R}$; without accounting for this negative correlation the coefficient for $A_{j}$ absorbs the negative effects of a lower $S_{j}^{R}$. Therefore, disregarding the endogeneity of firms' accreditation choices significantly underestimates the effectiveness of the accreditation system. Overall, the results show that although the accreditation status promotes quality, consumers tend to receive more information on quality from a firm's reputation than from the accreditation status.

\subsection{Welfare Analysis on the Value of Information}

I now exploit the advantage of a structural model with an underlying consumer utility maximization framework to quantify the impact of the accreditation mechanism on consumer welfare. The accreditation system can potentially affect consumer welfare through two channels. First, the accreditation status indicates an increase in quality of care by a certain level. It is possible that without this explicit mechanism in the long fun firms would "adversely select" into offering lower levels of quality. Second, the accreditation mechanism facilitates better consumer-product match by providing information. The information gain from the accreditation mechanism comes from 
consumers' more precise inferences about unobserved product quality, which helps consumers to choose the product they most desire. In this paper I think the more meaningful counterfactual is the one which focuses on the value of information provided by accreditation because my model is a short run model and I do not know the long run equilibrium if the accreditation system were eliminated. Therefore, for the following counterfactual I assume that childcare centers engage in quality differentiation with or without the accreditation mechanism. Without the mechanism, the centers would dissipate the information on their quality exclusively through their reputation.

With estimates of the structural parameters, I use the equivalent variation measure with discrete-choice models, developed by Small \& Rosen (1981), to assess consumer welfare for regimes with and without the accreditation system. The equivalent variation is the change in consumer wealth (expressed in monetary terms) that would be equivalent to the change in consumer welfare due to the price or quality change. In this study equivalent variation measures consumers' estimated aggregate welfare (expressed in dollar term) from receiving one hour of childcare services from the sampled firms. Basically, I calculate the change in consumer surplus in response to a regime change. ${ }^{42}$ One complication, in contrast to a real quality change, is that information only provides value by changing consumers' purchase decisions, because a consumer who does not switch gains (loses) no utility from learning their purchase has high (low) quality. I adapt Small and Rosen's methodology to capture this feature: in my calculation a consumer who does not switch to another provider in different regimes receives no welfare change.

Another adaptation I employ is to allow firms to adjust prices optimally under different information regimes. I combine the estimates of the structural parameters with firms' profit maximizing first order conditions to "back-out" the marginal cost of child care services. I assume that

\footnotetext{
${ }^{42}$ To be more specific, consumer welfare under the accreditation regime is the integral of the uncompensated demand from the equilibrium price levels to infinity. Suppose the government banned accreditation. Then the new consumer welfare would be the same integral from the new equilibrium price levels to infinity, with the demand as a function of the expected product quality given no accreditation. The welfare change can be derived from the comparison of the dollar numbers calculated under different regimes.
} 
revenues and costs for each type of service a childcare center provide are additive. Center $j$ maximizes its total profit over prices and accreditation decisions, ${ }^{43}$ holding other firms' accreditation status and pricing decisions constant:

$$
\max _{P_{g j}, A_{j}} \Pi_{j}\left(P_{g j}, A_{j}\right)=\sum_{g}^{1, \ldots, G} P_{g j} * Q_{g j}\left(P_{g j}, A_{j}\right)-m c_{g j} * Q_{g j}\left(P_{g j}, A_{j}\right)-C_{A} * A_{j}
$$

where $Q_{g j}$ is the quantity for each product $g$ of firm $j$ (enrollment for each age group), $m c_{g j}$ is the marginal cost of product $g$ of firm $j$, and $C_{A}$ is the cost of receiving accreditation. First order conditions with respect to $P_{g j}$ yield:

$$
m c_{g j}=\frac{\partial\left[P_{g j} * Q_{g j}\left(P_{g j}, A_{j}\right)\right] / \partial P_{g j}}{\partial Q_{g j}\left(P_{g j}, A_{j}\right) / \partial P_{g j}}=\left(1-\frac{1}{\alpha\left(1-m s_{g j}\right)}\right) P_{g j}
$$

where $m s_{g j}$ is the market share of product $g$ of firm $j$. I estimate marginal costs for care per hour from the above equation (the average of estimated marginal cost is \$0.99). I then derive the optimal prices set under the non-accreditation regime, which on average are only slightly lower than the prices under the accreditation regime,${ }^{44}$ and redo the welfare analysis with the adjusted prices.

A restriction of this welfare analysis is that I hold the accreditation status, and in turn the utility levels, of a firm's competitors constant over the two regimes because I do not have detailed information on the competitors of the sampled firms in the data. However, the cost-benefit analysis I will conduct below is based on an individual firm so it is still a meaningful exercise.

Table 8 reports results of the above welfare analysis. The first column reports consumer welfare under accreditation. The second reports consumer welfare under the non-accreditation regime without price adjustments, and the third column, with price adjustments. With accreditation, consumers' estimated aggregate welfare of receiving one hour of childcare services from the sampled

\footnotetext{
${ }^{43}$ Given that a majority of childcare centers are not for profit, the assumption of profit maximization is flawed. Still, this exercise remains worthwhile as a comparison to the no-price-adjustment regime.

${ }^{44}$ Note that I assume that firms still engage in quality differentiation without the accreditation system so the mean utility levels should be roughly the same from the accreditation to the non-accreditation regime.
} 
firms is approximately $\$ 232.1 \mathrm{~K}$. With accreditation eliminated, the welfare decreases to approximately $\$ 227.7 \mathrm{~K}$ (with no price adjustments) or $\$ 227.5 \mathrm{~K}$ (with price adjustments). That is, consumers of the sampled firms are willing to pay up to about $\$ 4,400$ to $\$ 4,600$ for the accreditation mechanism for one hour of childcare services at the sampled firms. The welfare impact of the accreditation mechanism is herein estimated to be $1.93 \%$ (with no price adjustments) and $2.01 \%$ (with price adjustments).

Although the welfare increase due to the accreditation mechanism seems economically significant, a cost-benefit analysis may reveal otherwise. On the benefit side, consumers of an average individual firm in our sample will receive about $\$ 4.9$ ( $\$ 4,600$ divided by the total number of 938 firms) of increased welfare due to the accreditation system for one hour of services. Suppose an average consumer receives 20 hours of childcare services per week ${ }^{45}$ for 40 weeks a year from the sampled firms, then the total annual benefit consumers receive from an individual firm due to the existence of accreditation system is a little short of $\$ 4,000$ ( $\$ 4.9$ per hour times 20 hours times 40 weeks). On the cost side, even if we assume that the applying firm does not have to do anything substantial to meet the accreditation threshold, there are still three sources of expenses for an individual firm to utilize the accreditation system. The first source of expenses is the application fee. In 1990, a typical childcare center applying for accreditation paid $\$ 425$ to $\$ 650$ to NAEYC. The second source of expenses is the expense to actually go through the (lengthy) accreditation process, which is much more substantial than the nominal accreditation fee. It takes devoted time of childcare employees to finish paperwork in the self-study, make sure every aspect of the services fit the requirements of the accreditation criteria, and prepare for the reviewer teams and judging panels. According to NAEYC reports (Ethiel, 1997), "the accreditation process proved time-consuming and labor-intensive." A general complaint in the field is that the accreditation process takes too much time

\footnotetext{
${ }^{45}$ This estimate comes from the statistics on the largest age group, the preschooler group, of a typical child care center, which indicates part-timers and full-timers each account for about 50\% of the enrollment.
} 
and paperwork. For example, the accreditation process requires the center director to observe the dayto-day activities of classrooms and take notes. The center director needs to balance this timeconsuming task with other job requirements and cope with staff anxiety about being observed and about the potential changes. Let's assume it is the center director who has the qualification to evaluate the center as a whole and does the actual work given that all other employees are directly providing childcare. Suppose it takes a month of work for the director, who has an annual salary of $\$ 30,000,{ }^{46}$ to get it done. This amounts to $\$ 2,500$ in labor expenses. In addition to the labor expenses, there should also be materials costs which are only intended for the accreditation such as new rugs and equipment. For example, centers need to be cleaned and decorated for the reviewer teams. Let's say these expenses amount to $\$ 1,000$. Totaling the bills, we now have $\$ 3,500$ in expenses directly related to the accreditation application. The third source of expenses is related to maintaining accreditation, which should be similar in nature to expenses in the accreditation process. A particularly important factor adversely affecting the accreditation maintenance is the high turnover rate in this industry. Whitebook (1996) reports that "within six months of the observation over a quarter of the staff had left their jobs" and "turnover is killing the accredited programs." With each turnover of a position, the director has to maintain the quality of care with the new hires as well as complete the accreditation paperwork and satisfy the accreditation criteria, which often goes beyond quality maintenance. As child care is such labor-intensive work, satisfying the accreditation criteria often means repeating part, or even most, of the accreditation process. Let's give a conservative estimate of $\$ 2,000$, in labor expenses, as the maintenance cost. In summary, the cost directly related to application is about $\$ 4,000$, and the cost related to maintenance is about $\$ 2,000$ per year.

With the numbers in, we can now conduct a rough cost-benefit analysis from the view point of an individual childcare center considering accreditation. Recall that the accreditation status is good

\footnotetext{
${ }^{46}$ Various Internet salary search sites, such as salary.com and payscale.com. indicate that a child care director's annual salary ranges from $\$ 45,000$ to $\$ 55,000$ in 2009 , which is equivalent to $\$ 28,000$ to 35,000 in 1990 dollars based on CPI adjustment.
} 
for three years if the center maintains quality up to the accreditation level and passes the annual checkups from NAEYC. From the perspective of a childcare center evaluating the benefit of receiving accreditation, the dollar figure for three years amounts to approximately $\$ 12,000$ ( $\$ 4000$ annual payoff times 3 years). However, there is uncertainty of receiving accreditation due to wrongful expectations, oversight, and unforeseeable events. According the 1996 NAYEC statistics, the overall success rate is much lower than $50 \% .^{47}$ If we take a $50 \%$ success rate into consideration, the expected payoff of seeking accreditation is about $\$ 6,000$ ( $\$ 12,000$ times $50 \%$ success rate). The expected cost from seeking accreditation, although a rough estimate, easily exceeds $\$ 6,000$ for an average firm. There is a $50 \%$ probability of a firm having to incur expenses of $\$ 10,000(\$ 4,000$ in application plus $\$ 6,000$ for three years of maintenance) and another $50 \%$ probability of expenses of $\$ 4,000$ (application only). The expected cost of seeking accreditation is then $\$ 7,000$, exceeding the benefit by $\$ 1,000$. If we assume a more realistic, lower success rate, the gap between benefit and cost will be even larger. Overall, the above analysis reveals a picture illustrating the lack of incentives for an average childcare center to utilize the accreditation system. Note that I have not even considered the administrative cost of the NAEYC as an agency as it is not related to an individual firm's welfare in utilizing the accreditation system.

\section{Conclusion}

In this paper I formulate a model in which consumers gain information about product quality from two information channels ---- the accreditation status and the reputation of a firm. I estimate this model to assess the effectiveness and welfare impact of the accreditation mechanism in the childcare market. This study offers an alternative, and perhaps more fundamental, explanation for the discrepancies between theory and empirical work. The theoretic literature predicts that the lack of

\footnotetext{
${ }^{47}$ In 1996 about $20 \%$ of childcare centers applied for accreditation while merely $7.5 \%$ obtained the status.
} 
information will distort firm behavior and market operations, potentially to a significant extent, while many empirical studies detect only small or negligible effects of a particular type of information provision. Moreover, the theoretic literature predicts that firms should have sufficient incentives to voluntarily disclose verifiable quality information to consumers, while in reality voluntary disclosure is barely complete. I suggest that these discrepancies might be attributed to the lack of effectiveness of the information provision. Particularly in the childcare market, the lack of informativeness of the accreditation system may prevent more firms from seeking accreditation.

Non-profit accreditation has been adopted in a wide range of professions such as health, personal services, safety and environmental industries. My perspective and findings shed new light on how accreditation works in markets where informal information prevails. My approach can also be applied to any market, from processed foods to used cars to financial services, where consumers cannot observe quality prior to purchase, and where accreditation or other types of formal information provision exist.

Methodologically, my study contributes in two ways to firm-level empirical analysis. First, I complement the random sample of firms with the Business Census, which provides information on the competitors of the sampled firms in my data, to obtain information on the market shares of all competing firms. As the original methodology in Berry (1994) needs data on the universe of firms, my method highlights the under-explored research potential for sample firm-level data and offers a straightforward and easy-to-implement formula for future researchers. Second, I combine the use of fixed-effects estimation with instrumental variables to solve the endogeneity problem of both the accreditation status and prices. In this study, disregarding the endogeneity of prices would reverse the sign for the price coefficient; disregarding the endogeneity of firms' accreditation choices would significantly underestimate the effectiveness of the accreditation system. My approach, though requiring panel data, should be useful to researchers who encounter similar problems. 
Akerlof, G., (1970), "The Market for Lemons," the Quarterly Journal of Economics, Vol. 84, 488500.

Ackerberg, D., (2001), "Empirically Distinguishing Informative and Prestige Effects of Advertising," RAND Journal of Economics, Vol. 32, 100-118.

Ackerberg, D., (2003), "Advertising, Learning, and Consumer Choice in Experience Good Markets: A Structural Empirical Examination," International Economic Review, Vol. 44(3), 10071040 .

Bajari, P. \& A. Hortacsu, (2003), "Economic Insights from Internet Auctions," Journal of Economic Literature, Vol. 42 (2), 457-486.

Banejee, A.V. \& E. Duflo, (2000), "Reputation Effects and the Limits of Contracting: A Study of the Indian Software Industry," the Quarterly Journal of Economics, Vol. 115 (3), 989-1017.

Berry, S. T., (1994), "Estimating Discrete-choice Models of Product Differentiation," RAND Journal of Economics, Vol. 25, 242-262.

Berry S., J. Levinsohn and A. Pakes (1995), "Automobile Prices in Market Equilibrium," Econometrica, 60(4), 889-917.

Blau, D. M., \& A. P. Hagy, (1998), "The Demand for Quality in Child Care," Journal of Political Economy, Vol. 106(1): 104-46.

Blau, D. and N. Mocan, 2002, "The Supply of Quality in Child Care Centers," Review of Economics and Statistics, Vol. 84 (3), 483-496.

Bredekamp, S., \& S. Glowacki, (1996), "The First Decade of NAEYC Accreditation: Growth and Impact on the Field," NAEYC Accreditation: A Decade of Learning and the Years Ahead.

Chernew, M., G. Gowrisankaran, \& D. Scanlon, (2008), "Learning and the Value of Information: The Case of Health Plan Report Cards," Journal of Econometrics, Vol.144, 156-74.

Chipty, T., 1995, "Economic Effects of Quality Regulations in the Daycare Industry," American Economic Review Papers and Proceedings, Vol. 85 (3), 419-424.

Chipty, T. \& A. D. Witte, (1998), "Effects of Information Provision in a Vertically Differentiated Market," NBER Working Papers, \#6493.

Crawford, G. S., \& M. Shum, (2005), "Uncertainty and Learning in Pharmaceutical Demand," Econometrica, Vol. 73(4), 1135-1174.

Devine, D. G., \& B. W. Marion, (1979), "The Influence of Consumer Price Information on Retail Pricing and Consumer Behavior," American Journal of Agricultural Economics, Vol. 61(2), 228-37. 
Dranove, D., D. Kessler, M. McClellan, \& M. Satterthwaite, (2003), "Is More Information Better? The Effects of 'Report Cards' on Health Care Providers," Journal of Political Economy, Vol. 11(3), 555-588.

Ethiel, N., (1997), Reflections on NAEYC Accreditation: Learns Learned and Goals for the Future, published by National Association for the Education of Young Children.

Grossman, S., (1981), "The informational Role of Warranties and Private Disclosure about Product Quality", Journal of Law and Economics, Vol. 24, 461-489.

Farrell, J., (1986), "Voluntary Disclosure: Robustness of the Unraveling Result, Comments and Its Importance," Antitrust and Regulations, ed. R. Grieson, Lexington: Lexington Books.

Fox, J., (2007), "Semiparametric Estimation of Multinomial Discrete Choice Models Using a Subset of Choices," RAND Journal of Economics, 38(4), 1002-1019.

Helburn, S. W., (1995), Cost, Quality and Child Outcomes in Child Care Centers: Technical Report. Denver: Univ. Colorado, Dept. Econ., Center Res. Econ. Soc. Policy.

Hofferth, S. L., A. Brayfield, S. Deich, \& P. Holcomb, (1991), National Childcare Survey, 1990, the Urban Institute Press, Washington, D.C.

Hotz, V. J., \& M. Xiao, (2005), "Strategic Information Disclosure: the Case of Multi-Attribute Products with Heterogeneous Consumers," NBER Working Paper 11937.

Hotz, V. J., \& M. Xiao, (2005), “The Impact of Minimum Quality Standards on Firm Entry, Exit, and Product Quality: the Case of the Child Care Market," NBER Working Paper 11873.

Hotz, V. J., \& R. Kilburn, (1996), "Regulating Child Care: The Effects of State Regulations on Child Care Demand and Its Cost," Mimeo, UCLA.

Hubbard, T. (2002), "How Do Consumers Motivate Experts? Reputational Incentives in an Auto Repair Market," Journal of Law and Economics, Vol. 45 (2), 437-68.

Jin, G., (2005): "Competition and Disclosure Incentives: An Empirical Study of HMOs," forthcoming, Rand Journal of Economics, Vol. 36(1), 93-112.

Jin, G. and P. Leslie (2003), "The Effects of Information on Product Quality: Evidence from Restaurants Hygiene Grade Cards," the Quarterly Journal of Economics, Vol. 118(2), 409-451.

Jin, G. and P. Leslie (2008), "Reputation Incentives for Restaurant Hygiene," forthcoming, American Economic Journal (Microeconomics).

Jovanovic, B. (1982), “Truthful Disclosure of Information,” Bell Journal of Economics, Vol. 13, 3644.

Kisker, E. E., R. Maynard, A. Gordon, \& M. Strain, (1989), The Child Care Challenge: What Parents Need and What is Available in Three Metropolitan Areas, Princeton, NJ: Mathematica Policy Research, Inc. 
Lang, E. L., \& J. J. Card, (1992), A profile of childcare settings, center-based programs: A user's guide to the machine-readable files and documentation (data set 17-18), Los Altos, CA: Sociometrics Corporation, American Family Data Archive.

Matthews, S. \& A. Postlewaite, (1985), "Quality Testing and Disclosure," RAND Journal of Economics, Vol. 16, 328-40.

Milgrom, P. R., (1981), "Good News and Bad News: Representation Theorems and Applications", Bell Journal of Economics, Vol. 12, 380-391.

Milyo, J., \& J. Waldfogel, (1999), "The Effect of Price Advertising on Prices: Evidence in the Wake of 44 Liquormart", American Economic Review, Vol. 89(5), 1081-96.

Mocan, H. N., (2001), "Can Consumers Detect Lemons? Information Asymmetry in the Market for Child Care,” NBER Working Papers, \#8291.

Nelson, P., (1974), “Advertising as Information”, Journal of Political Economy, Vol. 81,729-754.

O’Neill, G. E., \& M. O’Connell, (2001), "State Estimates of Childcare Establishments: 1977-1997," Working Paper Series No. 55, U. S. Bureau of the Census.

Peisner-Feinberg, E., \& M. Burchinal, (1995), “Child Care Quality and Children's Developmental Outcomes,' Cost, Quality and Child Outcomes in Child Care Centers: Technical Report, ed. Helburn, S.W., Univ. Colorado, Dept. Econ., Center Res. Econ. Soc. Policy.

Riley, J., (10979), “Information Equilibrium”, Econometrica, Vol. 47, 331-359.

Shavell, S., (1994), "Acquisition and Disclosure of Information Prior to Sale," RAND Journal of Economics, Vol. 20, 183-95.

Small, K. A., and H. S. Rosen, (1981), "Applied Welfare Analysis with Discrete Choice Models," Econometrica, Vol. 49, 105-30.

Spence, M., (1973), "Job Market Signaling", Quarterly Journal of Economics, 87 (3): 355-374.

Stiglitz, J., E., (1989), "Imperfect Information in the Product Market," Handbook of Industrial Organization: Volume 1, ed. Schmalensee R. and D. W. Robert, Amsterdam: North-Holland.

Whitebook, M. (1996), "NAEYC Accreditation as an Indicator of Program Quality: What Research Tells us," NAEYC Accreditation: A Decade of Learning and the Years Ahead, edited by Sue Bredekamp and Barbara A. Willer.

Whitebook, M., C. Howes \& D. Phillips, (1990), "Who Cares? Child Care Teachers and the Quality of Care in America," Final Report of the National Child Care Staffing Study, Oakland, California: Child Care Employee Project. 


\section{Appendix: Deriving the Log Likelihood Function for FIML Estimation}

I estimate a system of equations: $\begin{aligned} & \widehat{\lambda}_{j}=X_{j}^{\prime} \beta_{2}+D_{j}^{\prime} \beta_{3}+\Phi\left(h_{0}+h_{1} R_{j}\right) \gamma A_{j}+v_{j} \\ & S_{j}^{A}=Z_{j}^{\prime} \pi+\xi_{j} \quad\left(A_{j}=1 \Leftrightarrow S_{j}^{A} \geq 0 ; A_{j}=0 \Leftrightarrow S_{j}^{A}<0\right)\end{aligned}$

where $v_{j}=\left(1-\Phi\left(h_{0}+h_{1} R_{j}\right)\right) S_{j}^{R}+\overline{\omega_{. j}}$ and $\overline{\omega_{j}} \sim N\left(0, \frac{\sigma_{\omega}^{2}}{\kappa_{j}}\right)$. I assume that $\xi_{j}$ is a mean zero error and normalize $\xi_{j} \sim N(0,1)$.

I define $M=\left[X_{j}, D_{j}, R_{j}, Z_{j}\right]$ and $\sigma_{j v}=\sqrt{\left(1-\Phi\left(h_{0}+h_{1} R_{j}\right)\right)^{2} \operatorname{var}\left(S_{j}^{R}\right)+\frac{\sigma_{\omega}^{2}}{\kappa_{j}}}$ Let $v_{j}^{*}=\frac{v_{j}}{\sigma_{j v}}$ and it follows that $v_{j}^{*} \sim N(0,1)$. I assume that $\xi_{j}$ and $v_{j}^{*}$ are jointly normally distributed, with a correlation coefficient of $\rho$.

I then derive:

$$
\begin{aligned}
& f\left(v_{j}^{*}, \xi_{j}>-Z_{j}{ }^{\prime} \pi \mid M\right)=\int_{-Z_{j}{ }^{\prime} \pi}^{\infty} \frac{1}{2 \Pi \sqrt{\left(1-\rho^{2}\right)}} e^{-\frac{\left(v_{j}^{*}+\xi_{j}{ }^{2}-2 \rho v_{j}^{*} \xi_{j}\right)}{2\left(1-\rho^{2}\right)}} d \xi_{j} \\
& =\int_{-Z_{j}^{\prime}}^{\infty} \frac{1}{2 \Pi \sqrt{\left(1-\rho^{2}\right)}} e^{-\frac{\left(1-\rho^{2}\right) v_{j}^{* 2}+\left(\xi_{j}-\rho v_{j}^{*}\right)^{2}}{2\left(1-\rho^{2}\right)}} d \xi_{j}=\phi\left(v_{j}^{*}\right) \Phi\left(\frac{Z_{j}^{\prime} \pi+\rho v_{j}^{*}}{\sqrt{1-\rho^{2}}}\right) \\
& f\left(v_{j}^{*}, \xi_{j}<-Z_{j}^{\prime} \pi \mid M\right)=\phi\left(v_{j}^{*}\right)\left(1-\Phi\left(\frac{Z_{j}^{\prime} \pi+\rho v_{j}^{*}}{\sqrt{1-\rho^{2}}}\right)\right)
\end{aligned}
$$

The log likelihood of the equation system is:

$$
\begin{aligned}
& \log L=\log \prod_{1}^{J}\left[f\left(\lambda_{j}, A_{j}=1 \mid M\right)\right]^{A_{j}}\left[f\left(\lambda_{j}, A_{j}=0 \mid M\right)\right]^{1-A_{j}} \\
& =\sum_{1}^{J}\left[A_{j} \ln \left(f\left(\lambda_{j}, \xi_{j}>-Z_{j}^{\prime} \pi \mid M\right)\right)+\left(1-A_{j}\right) \ln \left(f\left(\lambda_{j}, \xi_{j}<-Z_{j}{ }^{\prime} \pi \mid M\right)\right)\right] \\
& =\sum_{1}^{J}\left[A_{j} \ln \left(f\left(v_{j}^{*}, \xi_{j}>-Z_{j}^{\prime} \pi \mid M\right) \frac{\partial v_{j}^{*}}{\partial \lambda_{j}}\right)+\left(1-A_{j}\right) \ln \left(f\left(v_{j}^{*}, \xi_{j}<-Z_{j}^{\prime} \pi \mid M\right) \frac{\partial v_{j}^{*}}{\partial \lambda_{j}}\right)\right] \\
& =\sum_{1}^{J}\left[\ln \phi\left(v_{j}^{*}\right)-\ln \sigma_{j v}+A_{j} \ln \left(\Phi\left(\frac{Z_{j}^{\prime} \pi+\rho v_{j}^{*}}{\sqrt{1-\rho^{2}}}\right)\right)+\left(1-A_{j}\right) \ln \left(1-\Phi\left(\frac{Z_{j}^{\prime} \pi+\rho v_{j}^{*}}{\sqrt{1-\rho^{2}}}\right)\right)\right]
\end{aligned}
$$




\title{
Table 1 Variable Definition
}

\author{
Variable Name Description \\ Firm Attributes (data from 1990 Profile of Childcare Settings) \\ enrollment* \# of enrolled children \\ price_gj* hourly price for age group $g$ of firm $j$ \\ staff-child ratio* \# of staff members / enrollment \\ part-time* $\quad$ whether the age group offers only part-time (less than 20 hours per week) services $(=1$ if \\ yes; $=0$ otherwise) \\ full-time* $\quad$ whether the age group offers only full-time (more than 20 hours per week) services $(=1$ \\ if yes; $=0$ otherwise) \\ accredit NAEYC accreditation status (=1 if accredited; $=0$ otherwise) \\ \# employees \# of employees \\ $\%$ White $\%$ of children enrolled who are White \\ years \# of years in operation \\ licensed licensing status ( $=1$ if licensed; $=0$ otherwise) \\ for-profit for-profit status ( $=1$ if for-profit; $=0$ if non-profit) \\ chain $\quad$ chain status $(=1$ if chain; $=0$ otherwise) \\ listed in $R \& R \quad$ listed in a resource and referral agency ( $=1$ if listed; $=0$ otherwise) \\ subsidy $\quad$ subsidization status $(=1$ if subsidized by a federal, state or local agency; $=0$ otherwise) \\ public trans distance to public transportation (categorical) \\ random wage hourly wage of a randomly drawn teacher (as a measure of teacher qualification)
}

\section{Market Attributes (data from 1990 Census of Population unless otherwise noted )}

outside share* $\quad$ zip code: $\%$ of market size in non-center-based child care (estimated using various data sources ---- details in Section 4.1)

$\%$ college zip code: $\%$ of population over age 18 with a bachelor degree

$\%$ Black zip code: \% Black

m_income zip code: median household income (in \$1000s)

$\%$ female work zip code: \% of women in the labor force who are employed

$\%$ under13 zip code: \% of population under age 13

$\%$ urban zip code: $\%$ urban population

$\%$ mobile $\quad$ zip code: $\%$ of population over age 5 who moved from other county/state/country in last 5 years

\# centers $\quad$ zip code: \# of childcare establishments with payroll (data from 1992 Census of Business)

CCR\&R county: whether there exists a childcare resource and referral agency (=1 if yes; $=0$ if no) (data from Chipty and Witte's 1998 survey)

Note: variables with * have panel nature, which have variation across age-groups within a firm. 
Table 2 Summary Statistics at the Center Level

\begin{tabular}{|c|c|c|c|c|c|c|c|}
\hline \multirow[t]{2}{*}{ variable } & \multicolumn{2}{|c|}{ all firms } & \multicolumn{2}{|c|}{ accredited } & \multicolumn{2}{|c|}{ non-accredited } & \multirow[b]{2}{*}{ t-test } \\
\hline & mean & std. dev & mean & std. dev & mean & std.dev & \\
\hline \multicolumn{8}{|l|}{ Firm Attributes } \\
\hline Accredit & 0.151 & 0.359 & 1 & - & 0 & - & - \\
\hline enrollment & 66.247 & 47.405 & 71.789 & 55.870 & 65.259 & 45.701 & \\
\hline \# employees & 8.595 & 7.185 & 9.796 & 7.491 & 8.381 & 7.112 & $* *$ \\
\hline$\%$ White & 0.780 & 0.304 & 0.72 & 0.344 & 0.790 & 0.295 & $* *$ \\
\hline staff-child ratio & 0.141 & 0.090 & 0.160 & 0.122 & 0.137 & 0.083 & $* * *$ \\
\hline years & 11.040 & 10.417 & 12.926 & 15.201 & 10.703 & 9.283 & $* *$ \\
\hline licensed & 0.878 & 0.327 & 0.979 & 0.144 & 0.861 & 0.347 & $* * *$ \\
\hline for-profit & 0.381 & 0.486 & 0.458 & 0.500 & 0.367 & 0.482 & $* *$ \\
\hline chain & 0.059 & 0.235 & 0.085 & 0.279 & 0.054 & 0.226 & \\
\hline listed in $\mathrm{R} \& \mathrm{Rs}$ & 0.698 & 0.459 & 0.746 & 0.437 & 0.690 & 0.463 & \\
\hline subsidy & 0.294 & 0.456 & 0.352 & 0.479 & 0.284 & 0.451 & \\
\hline public trans & 2.824 & 2.005 & 2.739 & 2.075 & 2.839 & 1.993 & \\
\hline random wage & 6.775 & 4.687 & 7.077 & 4.168 & 6.721 & 4.775 & \\
\hline \multicolumn{8}{|c|}{ Market Attributes } \\
\hline$\%$ college & 0.139 & 0.078 & 0.137 & 0.080 & 0.139 & 0.077 & \\
\hline$\%$ Black & 0.139 & 0.219 & 0.172 & 0.268 & 0.133 & 0.209 & $*$ \\
\hline m_income & 32.916 & 12.299 & 33.790 & 14.235 & 32.760 & 11.924 & \\
\hline$\%$ female work & 0.942 & 0.033 & 0.938 & 0.032 & 0.942 & 0.033 & \\
\hline$\%$ under13 & 0.193 & 0.040 & 0.195 & 0.041 & 0.192 & 0.040 & \\
\hline$\%$ urban & 0.676 & 0.437 & 0.695 & 0.433 & 0.673 & 0.438 & \\
\hline$\%$ mobile & 0.208 & 0.108 & 0.210 & 0.106 & 0.208 & 0.108 & \\
\hline \# centers & 5.188 & 3.731 & 5.423 & 3.920 & 5.146 & 3.697 & \\
\hline CCR\&R & 0.884 & 0.321 & 0.901 & 0.299 & 0.881 & 0.324 & \\
\hline $\mathrm{N}$ & \multicolumn{2}{|c|}{938} & \multicolumn{2}{|c|}{142} & \multicolumn{2}{|c|}{796} & \\
\hline
\end{tabular}

Last column: two-sample t-test with equal variances. $*$ significant at $10 \%$; ** significant at $5 \%$; *** significant at $1 \%$. All the following tables adopt the same notation for significance levels. 
Table 3 Summary Statistics at the Age Group Level

\begin{tabular}{|c|c|c|c|c|c|c|c|c|}
\hline Variable & Obs & Mean & std.dev & Min & Max & $A=1$ & $\mathrm{~A}=0$ & t-test \\
\hline & & & & & & Mean & Mean & \\
\hline Infants (0-11 months) & 273 & & & & & & & \\
\hline \# enrolled & & 7.003 & 7.154 & 1 & 75 & 7.5 & 6.903 & \\
\hline market share & & 0.040 & 0.086 & 0.001 & 0.824 & 0.054 & 0.038 & \\
\hline outside share & & 0.914 & 0.126 & 0.045 & 0.993 & 0.903 & 0.917 & \\
\hline price & & 1.362 & 0.577 & 0.500 & 4.300 & 1.349 & 1.365 & \\
\hline staff-child ratio & & 0.324 & 0.215 & 0.067 & 2 & 0.341 & 0.321 & \\
\hline part-time & & 0.055 & 0.228 & 0 & 1 & 0.022 & 0.062 & \\
\hline full-time & & 0.897 & 0.304 & 0 & 1 & 0.935 & 0.890 & \\
\hline Toddlers (12-35 months) & 544 & & & & & & & \\
\hline \# enrolled & & 15.898 & 17.351 & 1 & 281 & 15.706 & 15.938 & \\
\hline market share & & 0.036 & 0.075 & 0.001 & 0.771 & 0.036 & 0.037 & \\
\hline outside share & & 0.912 & 0.111 & 0.053 & 0.999 & 0.915 & 0.911 & \\
\hline price & & 1.563 & 0.904 & 0.460 & 6.940 & 1.680 & 1.539 & \\
\hline staff-child ratio & & 0.212 & 0.127 & 0.042 & 1.430 & 0.220 & 0.210 & \\
\hline part-time & & 0.147 & 0.354 & 0 & 1 & 0.163 & 0.144 & \\
\hline full-time & & 0.700 & 0.459 & 0 & 1 & 0.652 & 0.710 & \\
\hline Preschoolers (36-59 months) & 852 & & & & & & & \\
\hline \# enrolled & & 42.483 & 33.617 & 3 & 234 & 44.935 & 42.006 & \\
\hline market share & & 0.097 & 0.126 & 0.003 & 0.979 & 0.097 & 0.097 & \\
\hline outside share & & 0.721 & 0.194 & 0.022 & 0.988 & 0.714 & 0.722 & \\
\hline price & & 1.666 & 0.994 & 0.145 & 13.555 & 1.746 & 1.651 & \\
\hline staff-child ratio & & 0.145 & 0.096 & 0.034 & 1.25 & 0.169 & 0.141 & $* * *$ \\
\hline part-time & & 0.316 & 0.465 & 0 & 1 & 0.302 & 0.318 & \\
\hline full-time & & 0.447 & 0.497 & 0 & 1 & 0.511 & 0.435 & $*$ \\
\hline School-age (60+ months) & 527 & & & & & & & \\
\hline \# enrolled & & 27.066 & 28.260 & 1 & 271 & 25.480 & 27.338 & \\
\hline market share & & 0.015 & 0.027 & 0.0001 & 0.366 & 0.017 & 0.015 & \\
\hline outside share & & 0.951 & 0.067 & 0.2 & 0.999 & 0.958 & 0.950 & \\
\hline price & & 1.644 & 0.668 & 0.01 & 5 & 1.650 & 1.643 & \\
\hline staff-child ratio & & 0.137 & 0.110 & 0.026 & 1 & 0.150 & 0.135 & \\
\hline part-time & & 0.514 & 0.500 & 0 & 1 & 0.481 & 0.520 & \\
\hline full-time & & 0.192 & 0.395 & 0 & 1 & 0.351 & 0.164 & $* * *$ \\
\hline
\end{tabular}


Table 4 Instruments for Accreditation

\begin{tabular}{|l|l|c|c|c|c|c|}
\hline Variable & Definition & Obs. & Mean & std.dev & Min & Max \\
\hline $\begin{array}{l}\text { state-set staff-child } \\
\text { ratio licensing } \\
\text { requirement }\end{array}$ & $\begin{array}{l}\text { minimum staff-child ratio } \\
\text { regulated by state, average across } \\
\text { age groups }\end{array}$ & 938 & 0.101 & 0.030 & 0.04 & 0.25 \\
\hline $\begin{array}{l}\text { accreditation cost } \\
\text { over capacity }\end{array}$ & $\begin{array}{l}\text { NAEYC accreditation cost } \\
\text { divided by center capacity, in \$ }\end{array}$ & 938 & 2.353 & 0.599 & 0.166 & 6.052 \\
\hline market 1-3 & $\begin{array}{l}\text { market structure dummy (=1 if } 1- \\
3 \text { centers; =0 otherwise) }\end{array}$ & 938 & 0.368 & 0.482 & 0 & 1 \\
\hline market 4-6 & $\begin{array}{l}\text { market structure dummy (=1 if 4- } \\
\text { 6 centers; =0 otherwise) }\end{array}$ & 938 & 0.330 & 0.471 & 0 & 1 \\
\hline
\end{tabular}


Table 5 Panel Analysis: Simple Logit model

\begin{tabular}{|c|c|c|c|}
\hline Dependent: $\widehat{\delta_{g j}}$ & (1) OLS & (2) Between Groups & (3) Within Groups \\
\hline group: $\log ($ price_gj) & $\begin{array}{l}0.232 \\
(0.089)^{* * *}\end{array}$ & $\begin{array}{l}0.388 \\
(0.116)^{* * *}\end{array}$ & $\begin{array}{l}-0.329 \\
(0.147)^{* *}\end{array}$ \\
\hline group: staff-child ratio & $\begin{array}{l}-1.869 \\
(0.233) * * *\end{array}$ & $\begin{array}{l}-1.588 \\
(0.398)^{* * *}\end{array}$ & $\begin{array}{l}-1.848 \\
(0.259) * * *\end{array}$ \\
\hline group: part-time & $\begin{array}{l}-0.11 \\
(0.095)\end{array}$ & $\begin{array}{l}0.581 \\
(0.124) * * *\end{array}$ & $\begin{array}{l}-1.533 \\
(0.130) * * *\end{array}$ \\
\hline group: full-time & $\begin{array}{c}0.235 \\
(0.092)^{* *}\end{array}$ & $\begin{array}{l}-0.092 \\
-0.143\end{array}$ & $\begin{array}{c}0.134 \\
(0.115)\end{array}$ \\
\hline accredit & $\begin{array}{l}0.49 \\
(0.179)^{* * *}\end{array}$ & $\begin{array}{c}0.514 \\
(0.232)^{* *}\end{array}$ & \\
\hline accredit* $\log ($ years $)$ & $\begin{array}{l}-0.195 \\
(0.081)^{* *}\end{array}$ & $\begin{array}{l}-0.196 \\
(0.101)^{*}\end{array}$ & \\
\hline $\log ($ years $)$ & $\begin{array}{l}0.141 \\
(0.036)^{* * *}\end{array}$ & $\begin{array}{l}0.169 \\
(0.046)^{* * *}\end{array}$ & \\
\hline licensed & $\begin{array}{c}0.249 \\
(0.134)^{*}\end{array}$ & $\begin{array}{l}0.723 \\
(0.132)^{* * *}\end{array}$ & \\
\hline for-profit & $\begin{array}{l}-0.462 \\
(0.073) * * *\end{array}$ & $\begin{array}{l}-0.369 \\
(0.093)^{* * *}\end{array}$ & \\
\hline chain & $\begin{array}{l}-0.166 \\
(0.125)\end{array}$ & $\begin{array}{l}-0.145 \\
(0.18)\end{array}$ & \\
\hline listed in $\mathrm{R} \& \mathrm{R}$ & $\begin{array}{l}-0.179 \\
(0.083)^{* *}\end{array}$ & $\begin{array}{l}-0.176 \\
(0.098)^{*}\end{array}$ & \\
\hline subsidy & $\begin{array}{l}-0.161 \\
(0.072)^{* *}\end{array}$ & $\begin{array}{l}-0.141 \\
-0.095\end{array}$ & \\
\hline public trans & $\begin{array}{l}0.097 \\
(0.019) * * *\end{array}$ & $\begin{array}{l}0.121 \\
(0.024)^{* * *}\end{array}$ & \\
\hline $\log ($ random wage $)$ & $\begin{array}{l}0.195 \\
(0.055)^{* * *}\end{array}$ & $\begin{array}{c}0.141 \\
(0.072)^{*}\end{array}$ & \\
\hline$\%$ college & $\begin{array}{l}2.663 \\
(0.676) * * *\end{array}$ & $\begin{array}{c}1.742 \\
(0.823)^{* *}\end{array}$ & \\
\hline$\%$ Black & $\begin{array}{l}-0.593 \\
(0.177) * * *\end{array}$ & $\begin{array}{l}-0.442 \\
(0.233)^{*}\end{array}$ & \\
\hline $\log (\mathrm{m}$ _income $)$ & $\begin{array}{l}-0.338 \\
(0.155)^{* *}\end{array}$ & $\begin{array}{l}-0.231 \\
(0.184)\end{array}$ & \\
\hline$\%$ female work & $\begin{array}{c}3.256 \\
(1.435)^{* *}\end{array}$ & $\begin{array}{c}3.276 \\
(1.727)^{*}\end{array}$ & \\
\hline$\%$ urban & $\begin{array}{l}-0.797 \\
(0.098) * * *\end{array}$ & $\begin{array}{l}-0.756 \\
(0.118) * * *\end{array}$ & \\
\hline$\%$ mobile & $\begin{array}{c}-0.033 \\
(-0.331)\end{array}$ & $\begin{array}{c}0.293 \\
(-0.417)\end{array}$ & \\
\hline CCR\&R & $\begin{array}{l}0.605 \\
(0.119)^{* * *}\end{array}$ & $\begin{array}{l}0.508 \\
(0.147)^{* * *}\end{array}$ & \\
\hline constant & $\begin{array}{l}-3.915 \\
(1.615)^{* *}\end{array}$ & $\begin{array}{l}-5.520 \\
(2.019) * * *\end{array}$ & $\begin{array}{l}-2.710 \\
(0.110) * * *\end{array}$ \\
\hline R-squared & 0.16 & 0.34 & 0.21 \\
\hline obs & 2196 & 2196 & 2196 \\
\hline$\#$ of id code & & 938 & 938 \\
\hline
\end{tabular}

Note: for all results tables, standard errors are in parenthesis. 
Table 6 Reduced-Form Firm Level Analysis

\begin{tabular}{|c|c|c|c|c|}
\hline Dependent: $\widehat{\lambda}_{j}$ & (1) OLS & $\begin{array}{l}\text { (2) Heckman- } \\
\text { corrected, one } \\
\text { instrument }\end{array}$ & $\begin{array}{l}\text { (3) Heckman- } \\
\text { corrected, four } \\
\text { instruments }\end{array}$ & $\begin{array}{l}\text { (4) Heckman- } \\
\text { corrected, eight } \\
\text { instruments }\end{array}$ \\
\hline accredit & $\begin{array}{l}0.839 \\
(0.299)^{* * *}\end{array}$ & $\begin{array}{c}1.378 \\
(1.933) \\
\end{array}$ & $\begin{array}{c}2.374 \\
(1.282)^{*} \\
\end{array}$ & $\begin{array}{l}2.474 \\
(1.051)^{* *}\end{array}$ \\
\hline accredit* $\log ($ years $)$ & $\begin{array}{l}-0.305 \\
(0.131)^{* *}\end{array}$ & $\begin{array}{l}-0.307 \\
(0.131)^{* *}\end{array}$ & $\begin{array}{l}-0.310 \\
(0.131)^{* *}\end{array}$ & $\begin{array}{l}-0.326 \\
(0.131)^{* *}\end{array}$ \\
\hline inv_mills & & -0.296 & -0.851 & -0.896 \\
\hline$E\left(S_{j}^{R} \mid A_{j}=1\right)$ & & $(1.048)$ & $(0.691)$ & $(0.552)$ \\
\hline $\log ($ years $)$ & $\begin{array}{c}0.314 \\
(0.059) * * *\end{array}$ & $\begin{array}{l}0.313 \\
(0.059) * * *\end{array}$ & $\begin{array}{c}0.31 \\
(0.059) * * *\end{array}$ & $\begin{array}{l}0.313 \\
(0.059)^{* * *}\end{array}$ \\
\hline licensed & $\begin{array}{l}0.277 \\
(0.167)^{*}\end{array}$ & $\begin{array}{c}0.207 \\
(0.299)\end{array}$ & $\begin{array}{c}0.078 \\
(0.232) \\
\end{array}$ & $\begin{array}{c}0.068 \\
(0.210) \\
\end{array}$ \\
\hline for-profit & $\begin{array}{l}-0.745 \\
(0.117) * * *\end{array}$ & $\begin{array}{l}-0.758 \\
(0.127) * * *\end{array}$ & $\begin{array}{l}-0.783 \\
(0.121) * * *\end{array}$ & $\begin{array}{l}-0.784 \\
(0.120) * * *\end{array}$ \\
\hline chain & $\begin{array}{l}-0.436 \\
(0.231)^{*}\end{array}$ & $\begin{array}{l}-0.453 \\
(0.239)^{*}\end{array}$ & $\begin{array}{l}-0.484 \\
(0.235)^{* *}\end{array}$ & $\begin{array}{l}-0.488 \\
(0.233)^{* *}\end{array}$ \\
\hline listed in $\mathrm{R} \& \mathrm{R}$ & $\begin{array}{l}-0.296 \\
(0.126)^{* *}\end{array}$ & $\begin{array}{l}-0.315 \\
(0.143)^{* *}\end{array}$ & $\begin{array}{l}-0.35 \\
(0.133) * * *\end{array}$ & $\begin{array}{l}-0.352 \\
(0.131)^{* * *}\end{array}$ \\
\hline subsidy & $\begin{array}{l}-0.56 \\
(0.120)^{* * *}\end{array}$ & $\begin{array}{l}-0.566 \\
(0.122) * * *\end{array}$ & $\begin{array}{l}-0.575 \\
(0.121)^{* * *}\end{array}$ & $\begin{array}{l}-0.575 \\
(0.121)^{* * *} \\
\end{array}$ \\
\hline pub_trans & $\begin{array}{l}0.119 \\
(0.030)^{* * *}\end{array}$ & $\begin{array}{l}0.120 \\
(0.030)^{* * *}\end{array}$ & $\begin{array}{c}0.121 \\
(0.030) * * *\end{array}$ & $\begin{array}{l}0.121 \\
(0.030)^{* * * *}\end{array}$ \\
\hline $\log ($ random wage $)$ & $\begin{array}{l}0.328 \\
(0.092) * * *\end{array}$ & $\begin{array}{l}0.318 \\
(0.100)^{* * *}\end{array}$ & $\begin{array}{l}0.298 \\
(0.095) * * *\end{array}$ & $\begin{array}{l}0.297 \\
(0.094)^{* * * *}\end{array}$ \\
\hline$\%$ college & $\begin{array}{c}4.103 \\
(1.050)^{* * *}\end{array}$ & $\begin{array}{l}4.209 \\
(1.116) * * *\end{array}$ & $\begin{array}{c}4.405 \\
(1.078) * * *\end{array}$ & $\begin{array}{l}4.418 \\
(1.067)^{* * * *}\end{array}$ \\
\hline$\%$ Black & $\begin{array}{l}-1.435 \\
(0.295) * * *\end{array}$ & $\begin{array}{l}-1.491 \\
(0.355) * * *\end{array}$ & $\begin{array}{l}-1.594 \\
(0.322) * * *\end{array}$ & $\begin{array}{l}-1.598 \\
(0.312)^{* * *}\end{array}$ \\
\hline $\log (\mathrm{m}$ _income $)$ & $\begin{array}{l}-0.036 \\
(0.234) \\
\end{array}$ & $\begin{array}{l}-0.089 \\
(0.299) \\
\end{array}$ & $\begin{array}{l}-0.187 \\
(0.264) \\
\end{array}$ & $\begin{array}{l}-0.192 \\
(0.252) \\
\end{array}$ \\
\hline$\%$ female work & $\begin{array}{c}1.668 \\
(2.224) \\
\end{array}$ & $\begin{array}{c}2.018 \\
(2.547) \\
\end{array}$ & $\begin{array}{c}2.665 \\
(2.366) \\
\end{array}$ & $\begin{array}{c}2.708 \\
(2.313) \\
\end{array}$ \\
\hline$\%$ urban & $\begin{array}{l}-1.174 \\
(0.150)^{* * *}\end{array}$ & $\begin{array}{l}-1.171 \\
(0.151)^{* * *}\end{array}$ & $\begin{array}{l}-1.166 \\
(0.150)^{* * *}\end{array}$ & $\begin{array}{l}-1.165 \\
(0.150)^{* * *} \\
\end{array}$ \\
\hline$\%$ mobile & $\begin{array}{l}-1.472 \\
(0.530) * * *\end{array}$ & $\begin{array}{l}-1.544 \\
(0.588) * * *\end{array}$ & $\begin{array}{l}-1.676 \\
(0.555) * * *\end{array}$ & $\begin{array}{l}-1.688 \\
(0.546) * * *\end{array}$ \\
\hline CCR\&R & $\begin{array}{l}1.064 \\
(0.188)^{* * *}\end{array}$ & $\begin{array}{l}1.066 \\
(0.188)^{* * *}\end{array}$ & $\begin{array}{c}1.070 \\
(0.188)^{* * *}\end{array}$ & $\begin{array}{l}1.07 \\
(0.188)^{* * * *}\end{array}$ \\
\hline constant & $\begin{array}{l}-4.808 \\
(2.582)^{*}\end{array}$ & $\begin{array}{l}-4.567 \\
(2.721)^{*} \\
\end{array}$ & $\begin{array}{l}-4.120 \\
(2.641) \\
\end{array}$ & $\begin{array}{l}-4.112 \\
(2.615) \\
\end{array}$ \\
\hline R-squared & 0.33 & 0.33 & 0.33 & 0.33 \\
\hline obs & 938 & 938 & 938 & 938 \\
\hline
\end{tabular}


Table $7 \quad$ MLE Estimates of Structural Parameters

\begin{tabular}{|c|c|c|c|c|}
\hline & $\begin{array}{l}\text { (1) Exogenous } \\
\text { accreditation }\end{array}$ & $\begin{array}{l}\text { (2) FMLE, one } \\
\text { instrument }\end{array}$ & $\begin{array}{l}\text { (3) FMLE, four } \\
\text { instruments }\end{array}$ & $\begin{array}{l}\text { (4) FMLE, eight } \\
\text { instruments }\end{array}$ \\
\hline$\gamma$ accredit & $\begin{array}{l}2.922 \\
(0.263)^{* * * *}\end{array}$ & $\begin{array}{l}3.524 \\
(1.609)^{* *}\end{array}$ & $\begin{array}{l}5.387 \\
(0.585)^{* * * *} \\
\end{array}$ & $\begin{array}{l}5.420 \\
(0.573)^{* * * *} \\
\end{array}$ \\
\hline$h_{0}$ & $\begin{array}{l}-0.882 \\
(0.188)^{* * * *}\end{array}$ & $\begin{array}{l}-0.597 \\
(0.504) \\
\end{array}$ & $\begin{array}{l}-\mathbf{0 . 2 3 5} \\
(0.085)^{* * *}\end{array}$ & $\begin{array}{l}-0.222 \\
(0.089) * *\end{array}$ \\
\hline$h_{1}$ (log_years) & $\begin{array}{l}-0.240 \\
(0.116)^{* *}\end{array}$ & $\begin{array}{l}-0.166 \\
(0.180)\end{array}$ & $\begin{array}{l}-0.090 \\
(0.031)^{* * * *}\end{array}$ & $\begin{array}{l}-0.094 \\
(0.032)^{* * * *}\end{array}$ \\
\hline mean $h_{j}$ & $\begin{array}{l}0.092 \\
(0.044)^{* *}\end{array}$ & $\begin{array}{c}0.179 \\
(0.156)\end{array}$ & $\begin{array}{l}0.339 \\
(\mathbf{0 . 0 3 8})^{* * *}\end{array}$ & $\begin{array}{l}0.341 \\
(0.030)^{* * *}\end{array}$ \\
\hline$\rho$ & $\begin{array}{l}0 \\
(n . a) \\
\end{array}$ & $\begin{array}{l}-0.149 \\
(0.372)\end{array}$ & $\begin{array}{l}-0.569 \\
(0.103) * * *\end{array}$ & $\begin{array}{l}-0.580 \\
(0.100) * * *\end{array}$ \\
\hline$\beta \log ($ years $)$ & $\begin{array}{l}0.249 \\
(0.046)^{* * *}\end{array}$ & $\begin{array}{l}0.255 \\
(0.047)^{* * *}\end{array}$ & $\begin{array}{l}0.258 \\
(0.052)^{* * *}\end{array}$ & $\begin{array}{l}0.260 \\
(0.053)^{* * *}\end{array}$ \\
\hline licensed & $\begin{array}{c}0.186 \\
(0.178) \\
\end{array}$ & $\begin{array}{c}0.138 \\
(0.214) \\
\end{array}$ & $\begin{array}{l}-0.016 \\
(0.202)\end{array}$ & $\begin{array}{l}-0.016 \\
(0.203)\end{array}$ \\
\hline for-profit & $\begin{array}{l}-0.742 \\
(0.112) * * *\end{array}$ & $\begin{array}{l}-0.750 \\
(0.114) * * *\end{array}$ & $\begin{array}{l}-0.777 \\
(0.121)^{* * *}\end{array}$ & $\begin{array}{l}-0.774 \\
(0.122) * * *\end{array}$ \\
\hline chain & $\begin{array}{l}-0.332 \\
(0.278)\end{array}$ & $\begin{array}{l}-0.349 \\
(0.280)\end{array}$ & $\begin{array}{l}-0.402 \\
(0.281) \\
\end{array}$ & $\begin{array}{l}-0.403 \\
(0.278) \\
\end{array}$ \\
\hline listed in $R \& R$ & $\begin{array}{l}-0.279 \\
(0.118) * *\end{array}$ & $\begin{array}{l}-0.295 \\
(0.125)^{* *}\end{array}$ & $\begin{array}{l}-0.340 \\
(0.130)^{* * *}\end{array}$ & $\begin{array}{l}-0.342 \\
(0.131) * * *\end{array}$ \\
\hline subsidy & $\begin{array}{l}-0.503 \\
(0.119) * * *\end{array}$ & $\begin{array}{l}-0.502 \\
(0.121) * * *\end{array}$ & $\begin{array}{l}-0.515 \\
(0.127)^{* * *}\end{array}$ & $\begin{array}{l}-0.515 \\
(0.127) * * *\end{array}$ \\
\hline pub_trans & $\begin{array}{l}0.105 \\
(0.026) * * *\end{array}$ & $\begin{array}{l}0.105 \\
(0.026)^{* * *}\end{array}$ & $\begin{array}{l}0.107 \\
(0.028) * * *\end{array}$ & $\begin{array}{l}0.107 \\
(0.028) * * *\end{array}$ \\
\hline $\log ($ random wage $)$ & $\begin{array}{c}0.326 \\
(0.098) * * *\end{array}$ & $\begin{array}{l}0.319 \\
(0.102)^{* * *}\end{array}$ & $\begin{array}{l}0.298 \\
(0.105)^{* * *}\end{array}$ & $\begin{array}{l}0.297 \\
(0.106) * * *\end{array}$ \\
\hline$\%$ college & $\begin{array}{l}4.143 \\
(1.019)^{* * *}\end{array}$ & $\begin{array}{c}4.121 \\
(1.036) * * *\end{array}$ & $\begin{array}{l}4.264 \\
(1.111)^{* * *}\end{array}$ & $\begin{array}{l}4.340 \\
(1.113)^{* * *}\end{array}$ \\
\hline$\%$ Black & $\begin{array}{l}-1.362 \\
(0.318) * * *\end{array}$ & $\begin{array}{l}-1.384 \\
(0.325)^{* * *}\end{array}$ & $\begin{array}{l}-1.499 \\
(0.336) * * *\end{array}$ & $\begin{array}{l}-1.512 \\
(0.337)^{* * *}\end{array}$ \\
\hline $\log (\mathrm{m}$ income $)$ & $\begin{array}{l}-0.120 \\
(0.214)\end{array}$ & $\begin{array}{l}-0.127 \\
(0.226)\end{array}$ & $\begin{array}{l}-0.229 \\
(0.229)\end{array}$ & $\begin{array}{l}-0.242 \\
(0.230)\end{array}$ \\
\hline$\%$ female work & $\begin{array}{c}1.999 \\
(1.401)\end{array}$ & $\begin{array}{c}2.234 \\
(1.610)\end{array}$ & $\begin{array}{l}3.188 \\
(1.488) * *\end{array}$ & $\begin{array}{c}3.052 \\
(1.492) * *\end{array}$ \\
\hline$\%$ urban & $\begin{array}{l}-1.150 \\
(0.130)^{* * *}\end{array}$ & $\begin{array}{l}-1.149 \\
(0.132) * * *\end{array}$ & $\begin{array}{l}-1.142 \\
(0.144) * * *\end{array}$ & $\begin{array}{l}-1.145 \\
(0.145) * * *\end{array}$ \\
\hline$\%$ mobile & $\begin{array}{l}-1.288 \\
(0.505)^{* *}\end{array}$ & $\begin{array}{l}-1.324 \\
(0.524) * *\end{array}$ & $\begin{array}{l}-1.506 \\
(0.546) * * *\end{array}$ & $\begin{array}{l}-1.511 \\
(0.549) * * *\end{array}$ \\
\hline CCR\&R & $\begin{array}{l}1.015 \\
(0.187) * * *\end{array}$ & $\begin{array}{c}1.015 \\
(0.189)^{* * *}\end{array}$ & $\begin{array}{c}1.022 \\
(0.205)^{* * *}\end{array}$ & $\begin{array}{c}1.024 \\
(0.206) * * *\end{array}$ \\
\hline constant & $\begin{array}{l}-4.142 \\
(2.136)^{*}\end{array}$ & $\begin{array}{l}-4.270 \\
(2.181)^{*}\end{array}$ & $\begin{array}{l}-4.060 \\
(2.332)^{*}\end{array}$ & $\begin{array}{l}-3.808 \\
(2.345)\end{array}$ \\
\hline Log Likelihood & -1718.5 & -2099.7 & -2095.3 & -2091.6 \\
\hline
\end{tabular}


Table 8 Consumer Welfare Analysis

\begin{tabular}{|c|c|c|c|}
\hline & $\begin{array}{c}(1) \\
\text { Estimated } \\
\text { Equilibrium }\end{array}$ & $\begin{array}{c}\text { (2) } \\
\text { No Accreditation, } \\
\text { no Adjusting Price }\end{array}$ & $\begin{array}{c}\text { (3) } \\
\text { No Accreditation, } \\
\text { Adjusting Price }\end{array}$ \\
\hline Mean price & 1.597 & 1.597 & 1.573 \\
\hline Consumer welfare & $\$ 232,060$ & $\$ 227,660$ & $\$ 227,480$ \\
\hline $\begin{array}{l}\% \text { welfare change from no } \\
\text { accreditation to accreditation }\end{array}$ & n.a & $1.93 \%$ & $2.01 \%$ \\
\hline
\end{tabular}

